\title{
JAMSTEC Model Intercomparision Project (JMIP)
}

\author{
Chihiro Kodama $^{1 *}$, Akira Kuwano-Yoshida ${ }^{2,1}$, Shingo Watanabe ${ }^{1}$, Takeshi Doi ${ }^{1}$, Hiroki Kashimura ${ }^{3}$, and Tomoe Nasuno ${ }^{1}$
}

The JAMSTEC Model Intercomparison Project (JMIP) provides a first opportunity to systematically compare multiple global models developed and/or used in JAMSTEC with the aim of moving toward better weather and climate predictions. Here, we evaluate climate simulations obtained from atmospheric models (AFES and MIROC5), atmospheric model with slab ocean (NICAM.12), and fully coupled model (SINTEX-F1 and SINTEX-F2). In these simulations, the sea surface temperature is fixed (for AFES and MIROC5) or nudged (NICAM.12, SINTEX-F1, and SINTEX-F2) to the observed historical one. We focus on the climatology and variability of precipitation and its associated phenomena, including the basic state, the energy budget of the atmosphere, extratropical cyclones, teleconnection, and the Asian monsoon. We further discuss the possible causes of similarities and differences among the five JMIP models. Though some or most of the dynamical and physical packages in the JMIP models have been developed independently, common model biases are found among them. The AFES and MIROC5, and the SINTEX-F1 and SINTEX-F2, show strong similarities. In many respects, NICAM.12 shows unique characteristics, such as the distributions of precipitation, shortwave radiation, and explosive extratropical cyclones and the onset of the Asian summer monsoon. To some extent, the similarities and differences among the JMIP models overlap with those among the Coupled Model Intercomparison Project Phase-5 (CMIP5) models, suggesting that JMIP can be used as a simple and in-depth version of CMIP to investigate the mechanisms of model bias. We suggest that this JMIP framework could be expanded to an intercomparison of weekly-to-seasonal scale weather forecasting; here, more fruitful discussion is expected through intensive collaboration among modeling and observation groups.

Keywords : Atmospheric model intercomparison, climate simulation, precipitation, large-scale circulation, radiation, teleconnection

Received 28 December 2017 ; Revised 3 August 2018 ; Accepted 16 August 2018

1 Japan Agency for Marine-Earth Science and Technology (JAMSTEC)

2 Disaster Prevention Research Institute, Kyoto University, Japan

3 Department of Planetology/Center for Planetary Science, Kobe University, Japan

\author{
*Corresponding author: \\ Chihiro Kodama \\ Japan Agency for Marine-Earth Science and Technology \\ 3173-25, Showa-machi, Kanazawa-ku, Yokohama, Kanagawa 236-0001, Japan \\ kodamac@jamstec.go.jp
}

Copyright by Japan Agency for Marine-Earth Science and Technology 


\section{Introduction}

In cooperation with universities and other research institutes, JAMSTEC (Japan Agency for Marine-Earth Science and Technology) has operated the Earth Simulator, a supercomputer with a peak performance of 1.3 PFLOPS, and developed and employed multiple general circulation models (GCMs) for weather and climate studies. Each GCM has its strength in terms of computational efficiency, spatial resolution, forecast skill, scale interaction, interdisciplinary purpose, and so on. Among them, the atmospheric GCM (AGCM) for the Earth Simulator (AFES; Enomoto et al. 2008), an atmospheric component of coupled general circulation model (CGCM) for the Earth Simulator (CFES; Enomoto et al. 2008), has been highly optimized for the Earth Simulator at JAMSTEC and can be run at a horizontal resolution of $O(10 \mathrm{~km})$. The Model for Interdisciplinary Research on Climate (MIROC; Watanabe et al. 2010) is widely used in universities and research institutes, primarily for climate research. The MIROC group is one of two major modeling groups in Japan that contribute to the Coupled Model Intercomparison Project (CMIP). The Multiscale Simulator for the Geoenvironment (MSSG; Takahashi et al. 2008) is a non-hydrostatic global atmospheric model with a Yin-Yang grid system that can simulate multiscale phenomena from global to urban scales on the Earth Simulator. The Non-hydrostatic Icosahedral Atmospheric Model (NICAM; Satoh et al. 2014), a non-hydrostatic global atmospheric model with an icosahedral grid system, has been developed and used for high-resolution weather and climate simulations on multi-platform environments including the Earth Simulator and the K computer, a 10PFLOPS supercomputer operated by RIKEN. The Scale Interaction Experiment-Frontier ver. 1 (SINTEX-F1) model (Luo et al. 2005b), a coupled atmosphere-ocean model, has improved seasonal predictions of El Niño/La Niña, the Indian Ocean Dipole (IOD), and their teleconnections. The SINTEX-F1 model has routinely provided real-time seasonal forecasts since 2005 (see http://www.jamstec.go. $\mathrm{jp} / \mathrm{frcgc} / \mathrm{research} / \mathrm{d} 1 /$ iod/e/seasonal/outlook.html). Recently, a revised CGCM called SINTEX-F2, which is a highresolution version with a dynamical sea-ice model, has been developed (Masson et al. 2012). Other than the above models, an operational numerical weather prediction model, the global spectral model (GSM) at the Japan Meteorological Agency (JMA), and an AGCM jointly developed at JMA and the Meteorological Research Institute (MRI-AGCM) (Mizuta et al. 2012) are major global models developed and used in Japan. Also noteworthy is that JAMSTEC has been operating the Earth Simulator, as well as fostering model developers, technical staff, and users, since 2002. Thus, JAMSTEC is a major hub for global model development, simulation, and application in Japan.

The diversity of global models is a result of the diversity of research in this field, and it is clear that there is currently no global model that can be perfectly applied to all cutting-edge research. Although the research focus differs among modeling groups, some issues common to all the models do exist. Obviously, model bias is a central concern for all modeling groups; therefore, a shared approach to model improvement, which has not been typically published in the literature, would help enhance our ability to research cutting-edge themes. The CMIP is an international framework for comparing the results of global models and provide climate projection information for the Intergovernmental Panel on Climate Change (IPCC). However, users of model data have experienced difficulties in analyzing model data with a deep understanding of the nature of the individual models. Also, model developers have found difficulties receiving feedback from users of the model data. The same issue exists between observation experts and model data users and between observation experts and model developers. As such, JAMSTEC, where model developers, model data users, and observation experts work together, can be the ideal institute at which to bridge these gaps.

These observations motivated us to launch the JAMSTEC Model Intercomparison Project (JMIP). As an initial step, the results of climate simulations from five participating models (AFES, MIROC5, NICAM.12, and SINTEX-F1 and -F2; hereafter, the JMIP models) were collected on a single data sever with the same data format. Except for MIROC5, these JMIP models have never been included in CMIP (although NICAM has been partially included). The collected datasets were evaluated and compared based on the wide variety of the expertise of the participants. We discussed the comparison results and exchanged details on the model configurations in bimonthly JMIP meetings.

In this paper, outcomes of the first phase of JMIP activity are summarized. In Section 2, the participating models are introduced. Experimental design and datasets are described in Section 3. Some key results 
are shown in Section 4: precipitation and zonal mean basic state in Section 4.1, atmospheric radiation in Section 4.2, extratropical cyclones in the Northwestern Pacific in Section 4.3, interannual variability of El Niño/La Niña and IOD in Section 4.4, and the Asian summer monsoon in Section 4.5. A summary and future perspectives are presented in Section 5.

\section{Models}

Table 1 shows the configurations of the models used in this study. In this section, the features, main scientific targets, and milestone papers of each model are summarized.

\subsection{AFES}

AFES is an AGCM for the Earth Simulator (Ohfuchi et al. 2004; Enomoto et al. 2008; Kuwano-Yoshida et al. 2010a). Since 1998, AFES has been developed by Frontier Research System for Global Change, Research Organization for Information Science and Technology (RIST), Earth Simulator Center and Application Laboratory in JAMSTEC. The original code of AFES was adopted from version 5.4.02 of an AGCM developed jointly by the Center for Climate System Research (CCSR) of the University of Tokyo and the Japanese National Institute for Environmental Sciences (NIES) (Numaguti et al. 1997). The first version of AFES achieved 26.58 TFLOPS on the ES, for which it received the Gordon Bell Award for Peak Performance at Super Computing 2002, held in Baltimore, MD, USA, November 2002 (Shingu et al. 2002). Now, most of algorithms for effective computation on ES used in AFES are adopted to other AGCMs compared in this study. Enomoto et al. (2008) improved the accuracy and efficiency of the Legendre transform and physical performance via the introduction of a new radiation scheme (MstrnX; Sekiguchi and Nakajima 2008) and convection scheme (Emanuel 1991; Emanuel and Živković-Rothman 1999; Peng et al. 2004); this new version was termed AFES version 2. AFES version 3 (AFES3), as used in the present comparison, introduced an improved PDF cloud scheme (Kuwano-Yoshida et al. 2010a). AFES is mainly used for mid- and high-latitude atmosphere-ocean interactions (Minobe et al. 2008; Kuwano-Yoshida et al. 2010b; Ogawa et al. 2012; Okajima et al. 2018), ensemble-based data assimilation (Miyoshi and Yamane 2007; Miyoshi et al.
2007), and weather predictability (Kuwano-Yoshida and Enomoto 2013; Sato et al. 2017). In addition, AFES is expanded to other planets such as AFES-Venus (Sugimoto et al. 2017; Takagi et al. 2018). In the present comparison, AFES3 was integrated with modest horizontal resolution T239 (approximately $0.5^{\circ}$ ) and 48 vertical levels of sigma coordinate from the surface to about $3 \mathrm{hPa}$ to understand roles of western boundary currents such as the Kuroshio and the Gulf Stream, which provide massive heat/moisture to atmosphere in midlatitudes. The National Oceanic and Atmospheric Administration (NOAA) $0.25^{\circ}$ daily sea surface temperature (SST) data (Reynolds et al. 2007) were used for the bottom boundary conditions. The dataset was used as a control experiment in O'Reilly et al. (2016), O'Reilly et al. (2017), and Kuwano-Yoshida and Minobe (2017).

\subsection{MIROC5}

MIROC5 is a version of the global climate model MIROC, which was included in CMIP5 (Watanabe et al. 2010). Its atmospheric component has a resolution of T85 $\left(1.4^{\circ}\right)$ with 40 vertical levels up to $3 \mathrm{hPa}$. The physical parameterizations included in the atmospheric component can be found in Table 1 (see Watanabe et al. 2010 for more details). In this paper, results of the AMIP-type simulation, in which observed SSTs and sea ice concentrations were given as the bottom boundary conditions of the AGCM, are compared with the results obtained from other models.

MIROC5 has been developed to study a wide variety of climate-scale phenomena, from internal variations in the climate system like the Arctic Oscillation (AO), tropical intraseasonal variations, $\mathrm{El}$ Niño/Southern Oscillation (ENSO), and Pacific Decadal Oscillation (PDO), to climate sensitivity, anthropogenic climate change and paleo climates (e.g. Chikira and Sugiyama, 2013; Watanabe et al. 2012; Chikamoto et al. 2013; Watanabe et al. 2013; Kamae and Watanabe 2013). In this regard, MIROC5 includes a coupled aerosol module SPRINTARS (Takemura et al. 2005) and considers feedback processes among aerosols, clouds, precipitation, radiation, atmospheric circulations, and land surface conditions. This is a unique strength of MIROC5 among other models.

\subsection{NICAM.12}

NICAM is a non-hydrostatic icosahedral atmospheric model (Tomita and Satoh 2004; Satoh et 


\begin{tabular}{|c|c|c|c|c|c|}
\hline Model name & AFES & MIROC5 & NICAM.12 & SINTEX-F1 & SINTEX-F2 \\
\hline Model description papers & $\begin{array}{l}\text { Ohfuchi et al. (2004), Enomoto } \\
\text { et al. (2008), Kuwano-Yoshida } \\
\text { et al. (2010a) }\end{array}$ & "Watanabe et al. (2010) & $\begin{array}{l}\text { Tomita and Satoh (2004), Satoh } \\
\text { et al. }(2008,2014)\end{array}$ & $\begin{array}{l}\text { Roeckner et al. (1996), Gualdi } \\
\text { et al. (2003), Luo et al. (2005b) }\end{array}$ & $\begin{array}{l}\text { Roeckner et al. (2003), Masson } \\
\text { et al. (2012), Sasaki et al. } \\
\text { (2013) }\end{array}$ \\
\hline Dynamical core & $\begin{array}{l}\text { Hydrostatic spectrum model, } \sigma \\
\text { coordinate }\end{array}$ & $\begin{array}{l}\text { Hydrostatic spectrum model, } \\
\text { hybrid } \sigma \text {-p coordinate }\end{array}$ & $\begin{array}{l}\text { Non-hydrostatic finite volume } \\
\text { model, } z^{*} \text { (terrain-following) } \\
\text { coordinate }\end{array}$ & $\begin{array}{l}\text { Hydrostatic spectrum model, } \\
\text { hybrid } \sigma \text {-p coordinate }\end{array}$ & $\begin{array}{l}\text { Hydrostatic spectrum model, } \\
\text { hybrid } \sigma \text {-p coordinate }\end{array}$ \\
\hline Radiation & $\begin{array}{l}\text { MstrnX (Sekiguchi and } \\
\text { Nakajima 2008) }\end{array}$ & $\begin{array}{lll}\text { MstrnX (Sekiguchi and } \\
\text { Nakajima 2008) }\end{array}$ & $\begin{array}{l}\text { MstrnX (Sekiguchi and } \\
\text { Nakajima 2008) }\end{array}$ & $\begin{array}{l}\text { SW scheme (Fouquart and } \\
\text { Bonnell 1980) and LW scheme } \\
\text { (Morcrette 1991) }\end{array}$ & $\begin{array}{l}\text { SW scheme (Fouquart and } \\
\text { Bonnell 1980) and LW scheme } \\
\text { (Mlawer et al. 1997) }\end{array}$ \\
\hline Cumulus convection & $\begin{array}{l}\text { Emanuel (1991), Emanuel and } \\
\text { Živković-Rothman (1999) }\end{array}$ & Chikira and Sugiyama (2010) & Not used & Tiedtke (1989) & $\begin{array}{lll}\begin{array}{l}\text { Tiedtke } \\
(1994)\end{array} & (1989), & \text { Nordeng } \\
\end{array}$ \\
\hline Large-scale condensation & Kuwano-Yoshida et al. (2010a) & Watanabe et al. (2009) & Not used & Roeckner et al. (1996) & Roeckner et al. (2003) \\
\hline Cloud microphysics & None & $\begin{array}{l}\text { Bulk scheme (Wilson and } \\
\text { Ballard 1999) }\end{array}$ & $\begin{array}{l}\text { Single-moment six-category } \\
\text { bulk scheme (Tomita 2008) }\end{array}$ & None & None \\
\hline Turbulence & $\begin{array}{l}\text { MYNN Level-2 (Nakanishi } \\
\text { and Niino 2004) }\end{array}$ & $\begin{array}{l}\text { MYNN Level-2.5 (Nakanishi } \\
\text { 2001; Nakanishi and Niino } \\
\text { 2004) }\end{array}$ & $\begin{array}{l}\text { Modified MYNN Level-2 } \\
\text { (Nakanishi and Niino 2006; } \\
\text { Noda et al. 2010) }\end{array}$ & Brinkop and Roeckner (1995) & Brinkop and Roeckner (1995) \\
\hline Land model & MATSIRO (Takata et al. 2003) & MATSIRO (Takata et al. 2003) & MATSIRO (Takata et al. 2003) & Roeckner et al. (1996) & Roeckner et al. (2003) \\
\hline Ocean model & Not used & Not used & $\begin{array}{l}\text { Slab ocean model of } 15 \\
\mathrm{~m} \text { depth, nudging with a } \\
\text { relaxation time of } 7 \text { days }\end{array}$ & $\begin{array}{l}\text { Full OGCM, nudging } \\
\text { (damping rate: } \\
-2400 \mathrm{~W} \mathrm{~m}^{-2} \mathrm{~K}^{-1} \text { ) }\end{array}$ & $\begin{array}{l}\text { Full OGCM, nudging } \\
\text { (damping rate: } \\
-2400 \mathrm{~W} \mathrm{~m}^{-2} \mathrm{~K}^{-1} \text { ) }\end{array}$ \\
\hline
\end{tabular}


al. 2008, 2014). It adopts a finite volume method with an icosahedral grid system to perform ultra-high-resolution simulations using a massive parallel supercomputer. The main scientific target of NICAM is tropical meteorology (see review in Satoh et al. 2014), specifically, convection, Madden-Julian Oscillation (MJO), tropical cyclones, diurnal cycles of precipitation, and so on. Diabatic heating by latent heat release is crucial to these studies, and GCMs with a horizontal resolution of $O(100 \mathrm{~km})$ rely on the cumulus convection scheme, which is known to be a primary cause of uncertainties (Randall et al. 2003). NICAM realistically simulates global climatology without the cumulus convection scheme using a $3.5-\mathrm{km}$ mesh (or even a 14-km mesh) and can eliminate the ambiguity associated with the choice of convection scheme. On the first generation of the Earth Simulator, MJO was simulated for the first time using 3.5-km mesh NICAM (Miura et al. 2007). Continuous model development and enhanced computational power have improved model performance and promoted grand challenge simulations. In terms of horizontal resolution, the first-ever global cloud resolving simulation was achieved with a mesh size of $870 \mathrm{~m}$ (Miyamoto et al. 2013) and was continued for two days (Yashiro et al. 2016a). Though horizontal resolution of at least $2 \mathrm{~km}$ is necessary to resolve convection cores with multiple grids (Miyamoto et al. 2013), the statistical features of the convection and clouds except for shallow convection can be practically simulated using $14 \mathrm{~km}$ mesh model (e.g. Noda et al. 2010, 2012; Pauluis and Garner 2006). Present and future climate simulations using 14-km mesh NICAM were performed (Kodama et al. 2015; Satoh et al. 2015) and analyzed in terms of intraseasonal variation (Kikuchi et al. 2017), tropical synoptic-scale disturbance (Fukutomi et al. 2015), tropical cyclones (Satoh et al. 2015; Yamada et al. 2017), and climate sensitivity (Chen et al. 2016). The performance of MJO prediction was statistically confirmed through 14-km mesh, 54-ensemble simulation (Miyakawa et al. 2014). An intensive effort is further devoted to testing massive ensemble simulations (Miyoshi et al. 2015; Yashiro et al. 2016b). A recently developed double moment bulk cloud microphysics scheme (Seiki and Nakajima 2014) shows better performance in simulating climatology in a more realistic manner (Seiki et al. 2015).

In this study, the output from the 30-yr climate simulation of NICAM.12 (the 2012 version), in which SST is nudged toward the observed historical one using slab ocean model, was used for an analysis; see Kodama et al. (2015) for a detailed description of the experiment and its performance.

\subsection{SINTEX-F1 and F2}

\subsubsection{SINTEX-F1}

SINTEX-F1, a fully coupled GCM, has been previously used for the Application Laboratory (APL) /JAMSTEC seasonal prediction system (Luo et al. 2005a,b). The atmospheric component (ECHAM4) has a resolution of T106 $\left(1.125^{\circ}\right)$ with 19 vertical levels (Roeckner et al. 1996). The oceanic component (OPA8) has a relatively coarse resolution of $2^{\circ} \times 2^{\circ}$ Mercator horizontal mesh but with a tropical refinement up to $0.58^{\circ}$ in the meridional direction (Madec et al. 1998). The coupling information is exchanged every two hours without correction by the Ocean Atmosphere Sea Ice Soil (OASIS) 2 coupler (Valcke et al. 2000). Sea ice cover is relaxed toward the observed monthly climatology. In this study, we analyzed the outputs generated using a relatively simple SST-nudging initialization scheme with the SINTEX-F1 CGCM (Luo et al. 2005a). Model SSTs are strongly nudged toward daily observations in a coupled model with a restoring time of 1-day using the weekly NOAA OISSTv2 (Reynolds et al. 2002). The seasonal prediction system based on SINTEX-F1 has so far demonstrated high prediction performance for the ENSO (Luo et al. 2005a, 2008a; Jin et al. 2008), IOD (Luo et al. 2007, 2008b), subtropical dipole modes (Yuan and Yamagata 2015), and Coastal Niño (Doi et al. 2013, 2015a,b).

\subsubsection{SINTEX-F2}

The SINTEX-F2 coupled model, a higherresolution and upgraded version with a dynamical sea-ice model, has been developed to resolve several physical processes, particularly relatively small-scale phenomena in the ocean (Masson et al. 2012; Sasaki et al. 2013). The atmospheric component (ECHAM5) has a horizontal resolution of T106 (same as the SINTEX-F1 model) with 31 vertical levels (Roeckner et al. 2003). The oceanic component (OPA9) has the horizontal resolution of a $0.5^{\circ}$ $\times 0.5^{\circ}$ tri-polar grid (known as the ORCA05 configuration) with 31 vertical levels, similar to the SINTEX-F1 system (Madec 2008). While no sea ice model is incorporated in the SINTEX-F1 system, the dynamical sea ice model of the Louvain-la-Neuve Sea Ice Model (LIM) version 2 (LIM2) (Fichefet and Morales Maqueda 1997) is embedded in the SINTEX-F2 system. Although the atmospheric and 


\begin{tabular}{|c|c|c|c|c|c|}
\hline Model name & AFES & MIROC5 & NICAM.12 & SINTEX-F1 & SINTEX-F2 \\
\hline Description papers & O’Reilly et al. (2016) & Watanabe et al. (2010) & Kodama et al. (2015) & Luo et al. (2005b) & Doi et al. (2016) \\
\hline $\begin{array}{ll}\text { Horizontal } & \text { resolution, } \\
\text { number of grids } & \end{array}$ & $\mathrm{T} 239\left(\sim 0.5^{\circ}\right), 720 \times 360$ & $\mathrm{~T} 85\left(\sim 1.4^{\circ}\right), 256 \times 128$ & glevel-9 $(\sim 14 \mathrm{~km}), 10 \times 4^{9}+2$ & T106 $\left(\sim 1.125^{\circ}\right), 320 \times 160$ & T106 $\left(\sim 1.125^{\circ}\right), 320 \times 160$ \\
\hline $\begin{array}{l}\text { Number of vertical levels, } \\
\text { model top height }\end{array}$ & $\mathrm{L} 48,3 \mathrm{hPa}$ & $\mathrm{L} 40,3 \mathrm{hPa}$ & $\mathrm{L} 38,40 \mathrm{~km}$ & $\mathrm{~L} 19,10 \mathrm{hPa}$ & $\mathrm{L} 31,10 \mathrm{hPa}$ \\
\hline Integration term & $\begin{array}{l}\text { 1 September 1981-31 August } \\
2001\end{array}$ & $\begin{array}{l}1 \text { January 1979-31 December } \\
2008\end{array}$ & $\begin{array}{llll}1 & \text { June } & 1978-31 & \text { December } \\
2008 & & \end{array}$ & 1 January 1982-present & 1 January 1982-present \\
\hline $\begin{array}{l}\text { Sea surface temperature / Sea } \\
\text { ice }\end{array}$ & 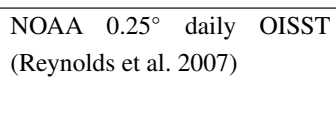 & $\begin{array}{l}\text { CMIP5 AMIP2 } 1^{\circ} \text { monthly } \\
\text { (Taylor et al. 2000) }\end{array}$ & $\begin{array}{l}\text { HadISST1 } 1^{\circ} \text { monthly with } \\
\text { Taylor correction (Rayner et al. } \\
\text { 2003; Taylor et al. 2000) }\end{array}$ & $\begin{array}{l}\text { NOAA } 1^{\circ} \text { weekly } \\
\text { (Reynolds et al. 2002) }\end{array}$ & $\begin{array}{l}\text { NOAA } 1^{\circ} \text { weekly } \\
\text { (Reynolds et al. 2002) }\end{array}$ \\
\hline $\begin{array}{l}\text { Ozone } \\
\end{array}$ & $\begin{array}{l}\text { AMIP2 zonal mean monthly } \\
\text { climatology (Liang et al. 1997) }\end{array}$ & $\begin{array}{l}\text { See A2.2.1 of Eyring et al. } \\
\text { (2013) }\end{array}$ & $\begin{array}{l}\text { MRI-CTM output (Shibata et } \\
\text { al. 2005) under CCMVal REF2 } \\
\text { condition (Eyring et al. 2008) }\end{array}$ & $\begin{array}{llr}\text { Zonal mean monthly } \\
\text { climatology } & \text { (Fortuin } & \text { and } \\
\text { Kelder 1998) } & & \end{array}$ & $\begin{array}{l}\text { Zonal mean monthly } \\
\text { climatology (Fortuin and } \\
\text { Kelder 1998) }\end{array}$ \\
\hline $\mathrm{CO}_{2}$ & Constant mixing ratio & $\begin{array}{l}\text { CMIP5 (Hansen and Sato } \\
\text { 2004) }\end{array}$ & $\begin{array}{l}\text { CMIP5 (Hansen and Sato } \\
\text { 2004) }\end{array}$ & $\begin{array}{l}\text { Constant mixing ratio, } 348 \\
\text { ppmv }\end{array}$ & $\begin{array}{l}\text { Constant mixing ratio, } 348 \\
\text { ppmv }\end{array}$ \\
\hline Aerosol & $\begin{array}{l}\text { Given, monthly climatology } \\
\text { simulated by SPRINTARS }\end{array}$ & $\begin{array}{lll}\text { Calculated } & \text { online } & \text { with } \\
\text { SPRINTARS } & & \end{array}$ & None & $\begin{array}{l}\text { Given, monthly climatology } \\
\text { simulated by Global Aerosol } \\
\text { Data Set (GADS) (Koepke et } \\
\text { al. 1997) }\end{array}$ & $\begin{array}{l}\text { Given, monthly climatology } \\
\text { simulated by GADS (Koepke et } \\
\text { al. 1997) }\end{array}$ \\
\hline Insolation & Constant & $\begin{array}{lll}\begin{array}{l}\text { CMIP5 } \\
\text { constant }\end{array} & \text { historical } & \text { solar } \\
\end{array}$ & Constant $\left(1365 \mathrm{~W} \mathrm{~m}^{-2}\right)$ & Constant $\left(1365 \mathrm{~W} \mathrm{~m}^{-2}\right)$ & Constant $\left(1365 \mathrm{~W} \mathrm{~m}^{-2}\right)$ \\
\hline
\end{tabular}


oceanic fluxes are exchanged every two hours with no flux correction by means of the Ocean Atmosphere Sea Ice Soil, version 3 (OASIS3) coupler (Valcke et al. 2004), we here analyzed the outputs of the SST-nudging run; model SSTs are strongly nudged toward daily observations similar to SINTEX-F1. More details and an overview of the prediction skill based on retrospective seasonal forecast experiments are given by Doi et al. (2016) and Doi et al. (2017).

\section{Experimental designs and datasets}

The simulations were performed in general accordance with AMIP protocol (Gates 1992). The configuration of each model is summarized in Table 2. The horizontal resolution ranges by one digit (from around $150 \mathrm{~km}$ to $14 \mathrm{~km}$ ). The model top is placed inside the stratosphere or around the stratopause, and the interval of the vertical levels is similar among the models (as compared with the large differences in horizontal resolution). The observed SST boundary conditions were directly imposed in AFES and MIROC5, whereas they were imposed via nudging techniques in NICAM.12, SINTEX-F1, and SINTEX-F2, as shown in Table 1. Unless specified in the text, the analysis period is $1983-2000$, and the data are regridded to $2.5^{\circ}$ in longitude and latitude for the analysis. Abbreviations and observational dataset references used in this study are listed in Table 3.

\section{Results}

\subsection{Precipitation and zonal mean basic state}

Precipitation and zonal mean basic state are fundamental metrics for evaluating the hydrological,

Table 3. List of observational datasets.

\begin{tabular}{|c|c|c|}
\hline $\begin{array}{l}\text { Abbre- } \\
\text { viation }\end{array}$ & Full name & Reference \\
\hline CERES & $\begin{array}{l}\text { Clouds and Earth's Radiant Energy System } \\
\text { (CERES) EBAF-TOA Ed2.8 and EBAF- } \\
\text { Surface Ed } 2.8\end{array}$ & Loeb et al. (2009) \\
\hline GPCP & Global Precipitation Climatology Project & Adler et al. (2003) \\
\hline JRA-55 & Japanese 55-year reanalysis & $\begin{array}{l}\text { Kobayashi et al. } \\
(2015)\end{array}$ \\
\hline $\begin{array}{l}\text { JRA- } \\
\text { 55C }\end{array}$ & $\begin{array}{l}\text { Japanese 55-year reanalysis assimilating } \\
\text { conventional observations only }\end{array}$ & $\begin{array}{l}\text { Kobayashi et al. } \\
(2014)\end{array}$ \\
\hline OISSTv2 & $\begin{array}{l}\text { Optimum interpolation sea surface } \\
\text { temperature version } 2\end{array}$ & $\begin{array}{l}\text { Reynolds et al. } \\
(2002)\end{array}$ \\
\hline
\end{tabular}

dynamical, and thermodynamical aspects of the simulated climate. Figures 1 and 2 show annual mean precipitation climatology for GPCP observations and the JMIP
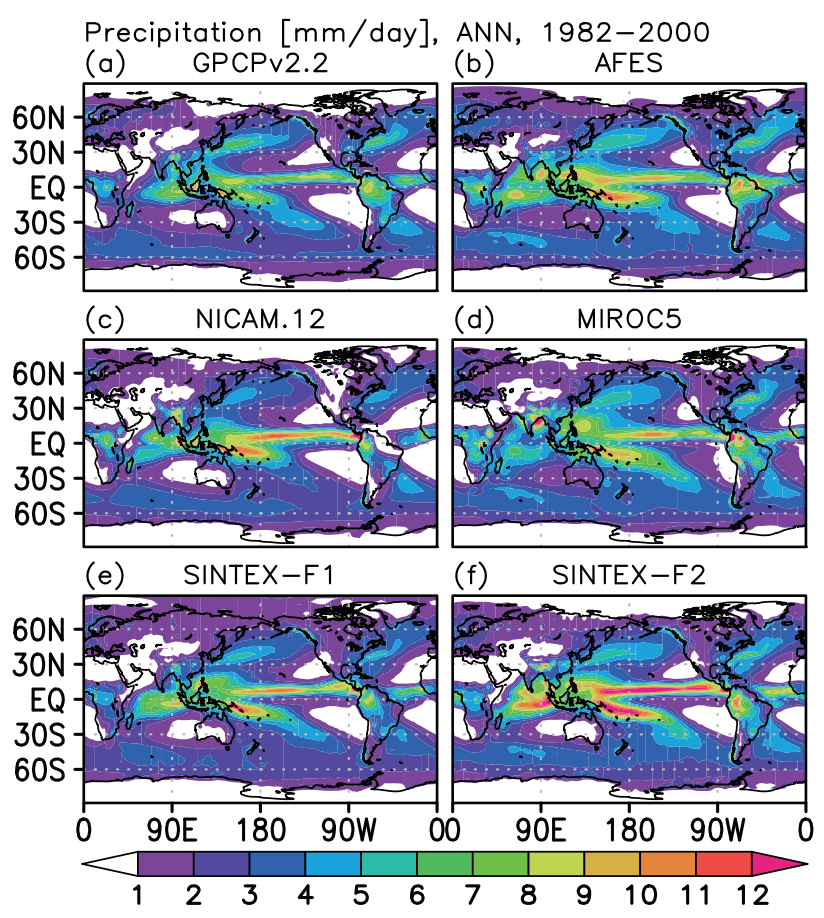

Fig. 1. Annual mean precipitation for GPCP version 2.2 (a) and JMIP models (b-f) [mm day $\left.{ }^{-1}\right]$.
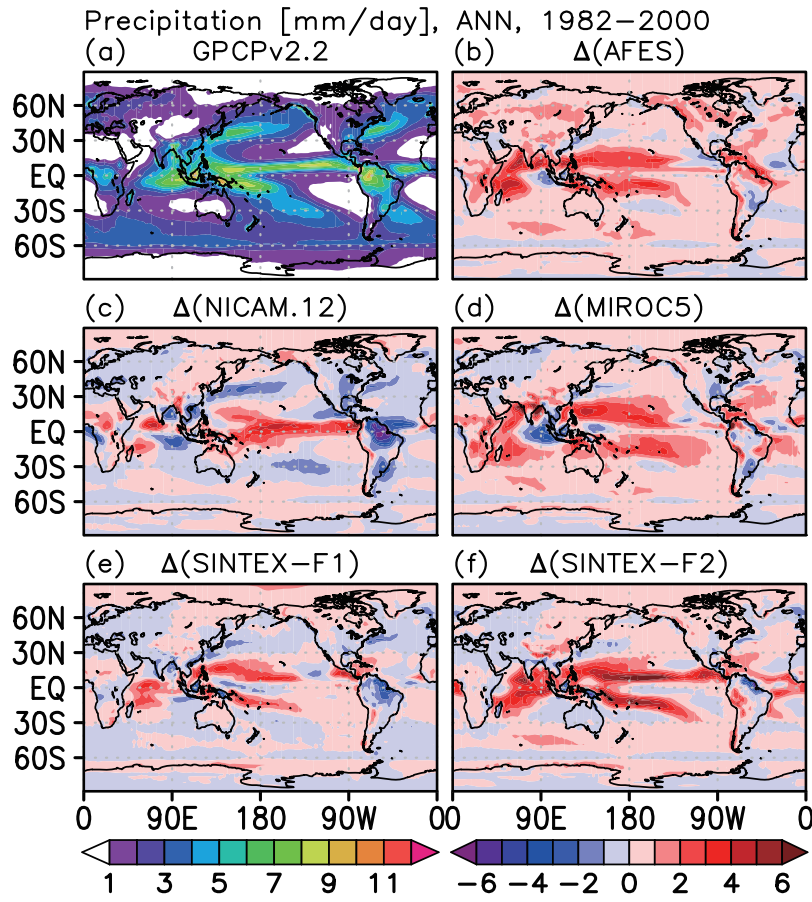

Fig. 2. Annual mean precipitation for GPCP version 2.2 (a, left color bar), and biases of the JMIP models from GPCP (b-f, right color bar). 
models. Their global means and the bias and root mean square error from the GPCP observations are shown in Table 4. Precipitation concentrates around the intertropical convergence zone (ITCZ) and storm-track regions. Over the Pacific, precipitation has a southern branch, the so called South Pacific convergence zone (SPCZ). Dry regions spread in the subtropics, where Hadley circulation descends. These qualitative patterns of the observed precipitation are simulated by all the JMIP models. As highlighted in Figs. 2b-f, all the models present excessive precipitation around the ITCZ. Among the JMIP models, AFES and MIROC5 show many similarities over oceans, such as excesses of tropical North and South Pacific precipitation (which is also seen in SINTEX-F1 and SINTEX-F2) and the east-west dipole structure of a precipitation bias over the Indian Ocean (which is also seen in NICAM.12). The reasons for this strong similarity may not be explained easily because these two models incorporate different physical parameterizations, such as cumulus convection and stratiform clouds (Table 1), and run under different horizontal and vertical resolutions (Table 2). The dipoletype precipitation bias over the Indian Ocean is not seen in the coupled version MIROC5 (Watanabe et al. 2010) and may be related to the treatment of air-sea interactions. SINTEX-F1 shows a similar bias pattern to SINTEX-F2, although SINTEX-F2 produces much more global mean precipitation compared with SINTEX-F1. This is partly due to new longwave (LW) and shortwave (SW) radiation schemes (Lohmann et al. 2007). Among the JMIP models, NICAM.12 has a unique precipitation bias pattern; that is, an excess of precipitation over the Central to Eastern Pacific at the equator and a lack of precipitation over South America. NICAM.12 best simulates the amount of global mean precipitation (Table 4), although it includes strong compensating biases. The annual mean precipitation patterns in the JMIP models vary widely such that we can expect a certain degree of model uncertainty in other weather and climate phenomena; this is described in the following sections.

The zonal mean temperatures and zonal winds for December-January-February (DJF) for the JRA-55 reanalysis and the JMIP models are shown in Figs. 3 and 4. All the JMIP models capture the fundamental structures of the thermodynamical and dynamical fields. All the JMIP models (except for AFES) have cold biases around the extratropical tropopause regions, especially in the
Southern Hemisphere. Among the models, AFES, MIROC5, and SINTEX-F2 well simulate zonal mean temperatures and zonal winds in the troposphere, whereas NICAM.12 and SINTEX-F1 have a warm bias in the tropical upper troposphere. In relation to this warm bias in the tropical upper troposphere and cold biases in the extratropical tropopause regions, NICAM.12 overestimates the wind speed of subtropical jets at their high-latitude flank.

Overall differences in the precipitation patterns and zonal mean basic states among the JMIP models may originate from differences in the (i) choice of physics scheme, (ii) horizontal and vertical resolutions, and (iii) target of the intensive model tuning. For example,

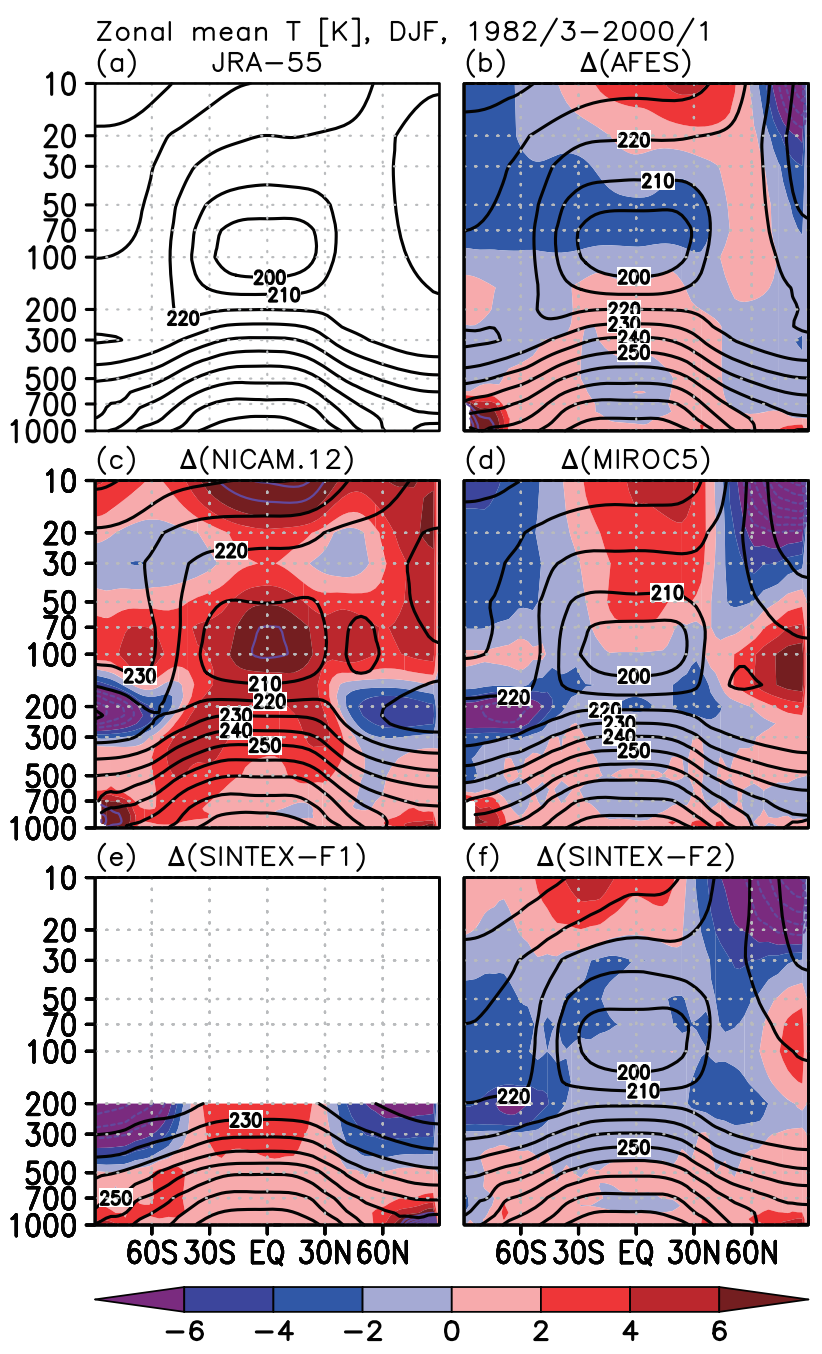

Fig. 3. Zonal mean temperature for December-January-February (DJF) during 1982/1983-2000/2001. (a) JRA-55 reanalysis. (b-f) JMIP models as black contours and their biases as shading and additional purple contours $( \pm 8 \mathrm{~K}, \pm 10 \mathrm{~K}, \ldots)$. Note that SINTEX-F1 did not output temperature above $200 \mathrm{hPa}$. 
NICAM.12, the main focus of which is moist processes of the tropical meteorology, uses a shallow slab ocean with SST nudging; this leads to a better performance of MJO (Grabowski 2006) and an reduction of the double ITCZ bias as a result (Kodama et al. 2015). However, this also leads to a bias in the extratropics, as described in Section 4.3. Note that NICAM.12 does not use convection and orographic gravity wave drag schemes, and biases in the zonal mean basic state described in this study have been reduced significantly in the latest version by updating of the cloud microphysics scheme (Seiki et al. 2015) as well as the inclusion of an orographic

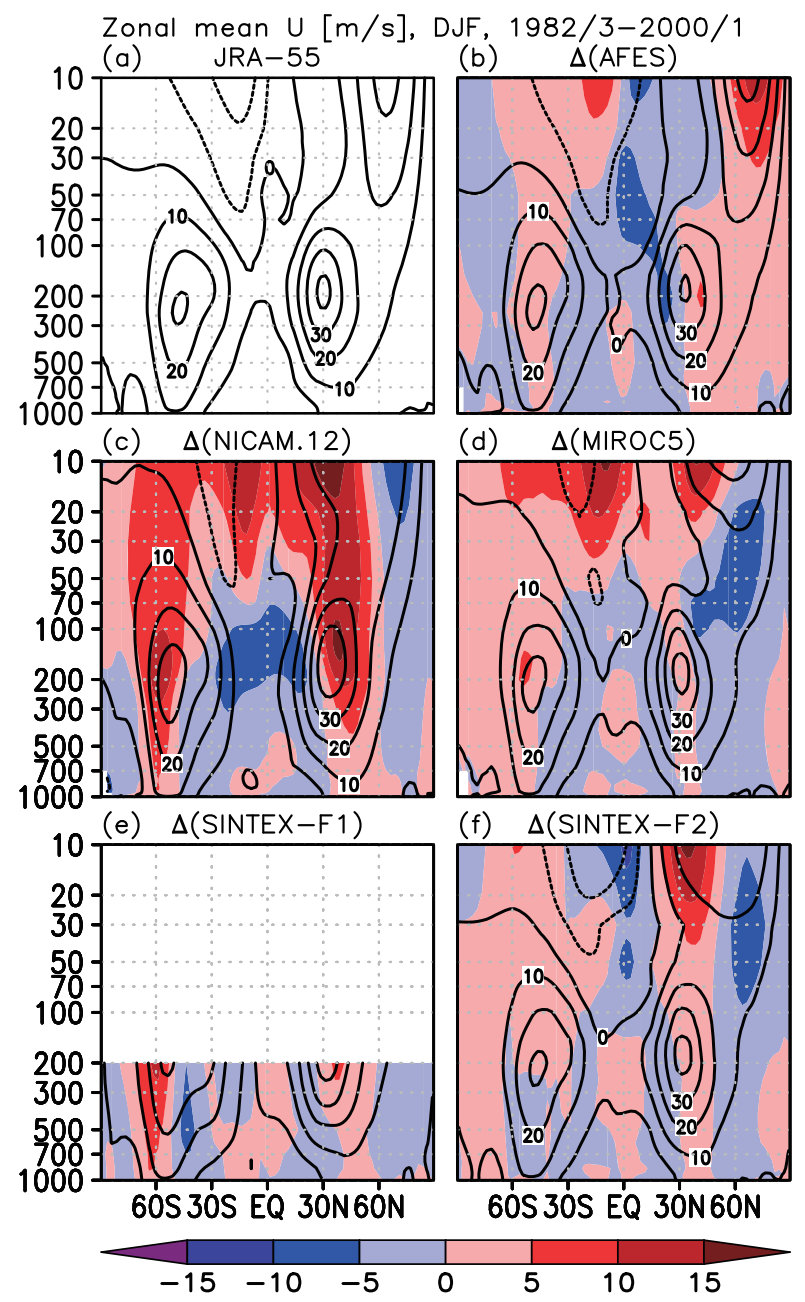

Fig. 4. Same as Fig. 3 but for zonal mean zonal wind. gravity wave drag scheme. This is one outcome of JMIP because all the other JMIP models use orographic gravity wave drag schemes to tune the mid-latitude jet.

These hydrological, thermodynamical, and dynamical aspects of the simulated climate are connected with other global and regional phenomena, as described in the following sections. Global mean precipitation is tightly connected with outgoing longwave radiation (OLR) (Section 4.2). The spatial precipitation pattern is related to local circulations including the Asian monsoon (Section 4.5) and storm-track (Section 4.3), whose interannual variabilities are affected by the ENSO, IOD, and their teleconnections (Section 4.4).

\subsection{Atmospheric reflection and absorption of SW radiation}

The energy balance of the radiation flux at the top of the atmosphere (TOA) is very important in simulations of Earth's climate. Table 5 shows temporally and globally averaged net fluxes of SW and LW radiation at the TOA, as calculated from the data of each model and observational products of the Clouds and Earth's Radiant Energy System (CERES) experiment (Wielicki et al. 1996). Here, we used the monthly averaged global data sets of CERES EBAFTOA Ed2.8 (Loeb et al. 2009) as observation data. Note that the averaging period for the five models is 1982-2000 and for CERES is 2001-2015; the difference of the averaging period is due to data availability. The net LW fluxes in the JMIP models (except for SINTEX-F2) show similar values $\left(-236.0 \pm 0.4 \mathrm{~W} \mathrm{~m}^{-2}\right)$. In SINTEX-F2, the equatorial OLR is higher than that in CERES and the other models (not shown). This is due to a shortage of clouds in SINTEX-F2, as suggested by the negative bias of the atmospheric albedo analyzed below; that is, the strong LW radiation from the warm near-surface atmosphere is less blocked by the clouds and reaches the TOA.

In contrast to the similarity observed in the LW fluxes, the inter-model difference in the net SW fluxes is as large as $14.5 \mathrm{~W} \mathrm{~m}^{-2}$. The fact that the inter-model difference in the net SW radiation flux is larger than that in the net LW radiation flux implies a large uncertainty in processes

Table 4. Statistics for annual mean precipitation (Figures 1 and 2). Global mean and bias and root mean square error from GPCP version 2.2 are shown in $\mathrm{mm} \mathrm{day}^{-1}$.

\begin{tabular}{lcccccc} 
& GPCP & GAFES & NICAM.12 & MIROC5 & SINTEX-F1 & SINTEX-F2 \\
\hline Global mean & 2.68 & 3.31 & 2.67 & 3.24 & 2.76 & 3.24 \\
Bias & & +0.63 & -0.01 & +0.56 & +0.08 & +0.56 \\
RMSE & & 1.19 & 1.22 & 1.36 & 0.94 & 1.49
\end{tabular}


related to SW radiation, such as reflection and absorption by the atmosphere and clouds. Donohoe and Battisti (2011) proposed a method to estimate the atmospheric albedo (i.e., reflection rate) and absorption rate for SW radiation from the upward and downward SW radiation fluxes at the TOA and the surface by assuming a single layer model of the atmosphere. Here, we adopt their methods and estimate the atmospheric albedo and absorption rate for the five models and the observational data (CERES EBAF-Surface Ed2.8 is used for the data at the surface).

Figures $5 \mathrm{a}$ and $5 \mathrm{~g}$ show a temporally averaged atmospheric albedo map and its zonal mean, respectively, for SW radiation calculated from the CERES data. Because the reflection rate depends on the solar zenith angle, higher albedo is generally observed at higher latitudes. Horizontal variation of the atmospheric albedo at low- and midlatitudes is mainly due to cloud; that is, cloudy regions show high albedo, whereas dry (non-cloudy) regions show low albedo. We confirm that the atmospheric albedo calculated from clear-sky values shows an almost zonally uniform distribution (not shown). Note that in recent years, a high albedo in China seems to be due to a large amount of $\mathrm{SO}_{2}$ emission (Klimont et al. 2013) caused by industrial growth. Model biases, as compared with CERES data, are shown in Figs. 5b-f and h. The four models (except for SINTEXF2) show higher albedo over the subtropical ocean where low albedo is observed. This implies that the albedo of the thin lower clouds above the ocean is overestimated in these models. On the other hand, there are negative biases in high albedo oceanic regions, such as the eastern part of Pacific in both hemispheres. This implies that the amounts of lower cloud in the cloudy regions are underestimated in the models. These results are consistent with Medeiros and Stevens (2011). They analyzed representations of lower clouds in four different GCMs and reported that the GCMs tend to overestimate the lower clouds due to the trade-wind inversion over the subtropical ocean and underestimate the marine stratocumulus in eastern part of Pacific (i.e., west coast). One of the most marked inter-model differences is the negative albedo bias of NICAM.12 on land, which seems to be due to a negative bias in the cloud fraction (Kodama et al. 2015) and the lack of aerosols in NICAM.12. Such a negative bias over a wide area results in a positive bias in the net SW radiation flux at the TOA, as shown in Table 5. The bias over the Maritime Continent also shows significant inter-model differences: negative in AFES, NICAM.12 and SINTEX-F2, and positive in MIROC5 and SINTEX-F1. This may be relevant to the difficulty in simulating realistic amounts of both precipitation and clouds over the Maritime Continent, where convection, the boundary layer, largescale condensation, radiation, and surface heat flux schemes would interact complexly with each other.

The atmospheric absorption rate for SW radiation is shown in Fig. 6. The SW absorption in the atmosphere is mainly due to water vapor. As such, a high absorption rate is observed above the ocean, especially in equatorial regions, and a low rate is observed in dry areas and high lands. Since the horizontal variation of water vapor at the synoptic scale and mesoscale is smaller than that of the clouds, and the absorption rate does not depend on the solar zenith angle, the horizontal distribution of the absorption rate is more uniform compared to that of the albedo. In polar regions, all the models show positive bias in the atmospheric SW absorption rate, possibly implying an overestimation of the water vapor amounts in these regions. Insufficient accuracy in modeling the latent and sensible surface heat fluxes in sea ice regions, which is a common problem in most global climate models, could be a reason for the overestimation of the water vapor amount in polar region. In fact, high temperature biases, which is equivalent to positive biases in saturated water vapor amount, are obtained in lower troposphere in polar region for all models as shown in Fig. 3b-f. Note that the absorption rate may be overestimated because of the positive bias in the surface albedo, which tends to be too high for snow and ice by tuning; however, this is not the case for at least the Antarctic Ocean. In most of the other regions, AFES, NICAM.12, and MIROC5 show negative bias, especially over the continents, whereas SINTEX-F1

Table 5. Globally and temporally averaged values of the net SW and LW radiation fluxes at the TOA, and those of the atmospheric albedo and absorption rate of SW radiation, for each model and observational dataset from CERES. The model-mean is also shown.

\begin{tabular}{lccccccc} 
& CERES & AFES & NICAM.12 & MIROC5 & SINTEX-F1 & SINTEX-F2 & Model-mean \\
\hline Net-SW [W/m ${ }^{2}$ ] & 240.6 & 240.2 & 249.4 & 235.3 & 238.0 & 245.8 & 241.7 \\
Net-LW [W/m ${ }^{2}$ ] & -239.7 & -236.4 & -236.1 & -235.6 & -236.0 & -245.3 & -237.9 \\
\hline Atmos. alb. & 0.286 & 0.281 & 0.241 & 0.297 & 0.304 & 0.276 & 0.280 \\
Atmos. abs. & 0.212 & 0.202 & 0.197 & 0.207 & 0.252 & 0.213 & 0.214 \\
\hline
\end{tabular}


shows a significantly positive bias. In SINTEX-F2, a positive bias is shown in the Eurasian Continent and northern part of the African Continent, and a negative bias is shown in other regions. Aerosols could be a reason for the observed biases over the continents; a relatively strong negative bias in NICAM.12 would be due to a lack of aerosols in the model, and a locally strong negative bias around China would be due to the difference in the averaging period between the CERES data and the models, which should reflect an increase of black carbon emission with industrial growth (Wang et al. 2012). The positive biases in SINTEX-F1 and SINTEXF2 suggest that the amount of aerosols is overestimated or the SW absorption rate of the aerosols is too high in these models.

The above analyses show that the inter-model differences in the net SW flux at the TOA would be caused by the differences in atmospheric albedo for SW radiation, which is mainly a result of the uncertainty in the cloud and radiative modeling as well as aerosol treatment.

\subsection{Explosive extratropical cyclones in the Northwestern Pacific}

Extratropical cyclones are the main phenomenon in the mid-latitude troposphere. In particular, explosive
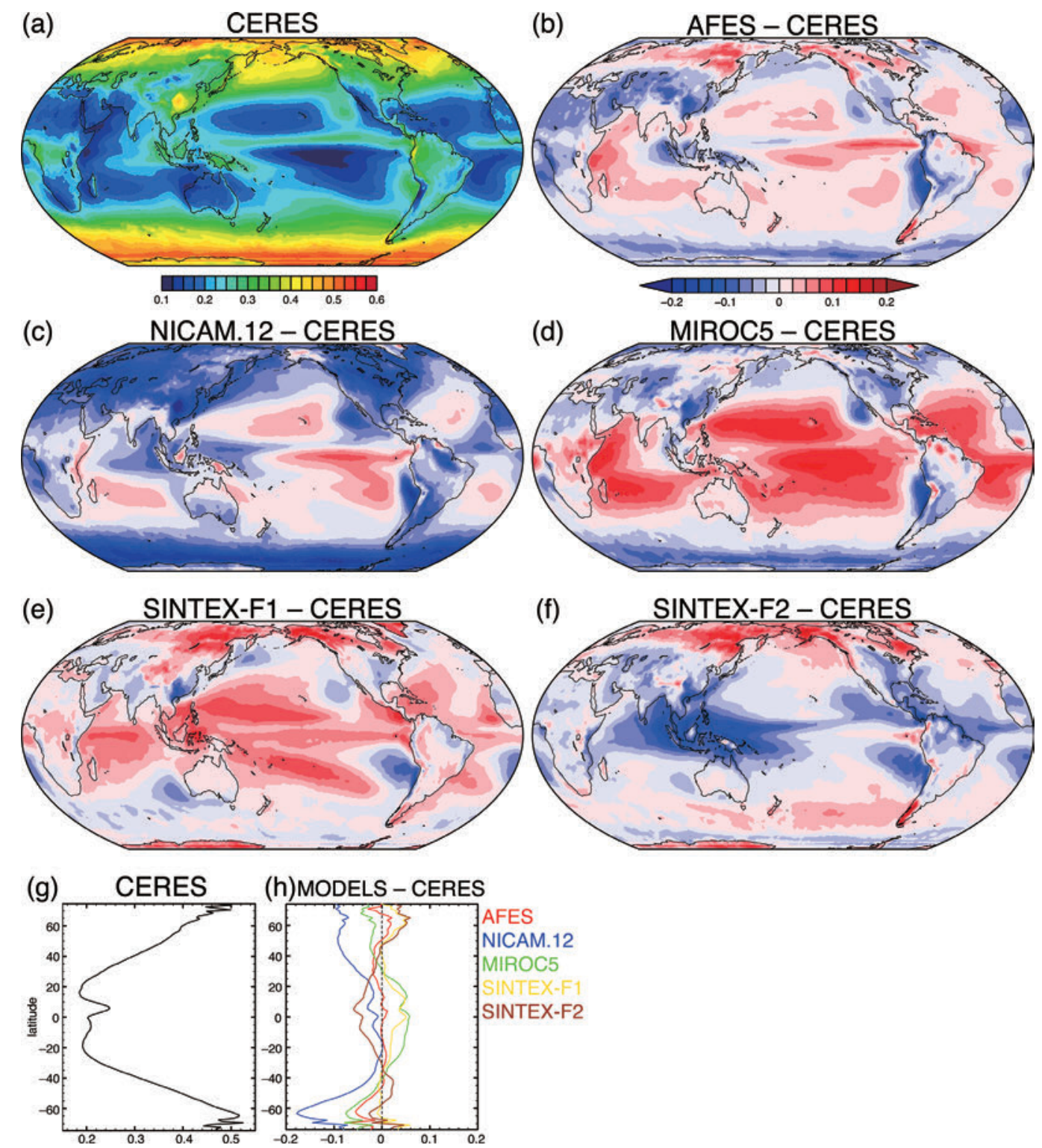

Fig. 5. (a) Atmospheric albedo map for SW radiation calculated from CERES data and (g) its zonal mean. Panel (h) shows the zonally averaged deviations of the models' values from CERES data. Other panels show the deviation maps for (b) AFES, (c) NICAM.12, (d) MIROC5, (e) SINTEX-F1, and (f) SINTEX-F2. Time-averaged data are used for each panel. 
extratropical cyclones are active in winter and their activity controls precipitation and jet stream meandering over oceans. Therefore, in this section, the activity of explosive extratropical cyclones in January over the Northwestern Pacific in the five JMIP models is investigated. Observations have shown that the Northwestern Pacific is the most active region in the world for explosive extratropical cyclones and their activity reaches a maximum in January. To estimate the activity of the cyclones, the Local Deepening Rate for 24 hours (LDR24, Kuwano-Yoshida 2014) index is used. This index uses the surface pressure local tendency for 24 hours:

$$
\mathrm{LDR} 24=-\frac{P_{s f c}(t+12 h)-P_{s f c}(t-12 h)}{24}\left|\frac{\sin 60^{\circ}}{\sin \theta}\right|,
$$

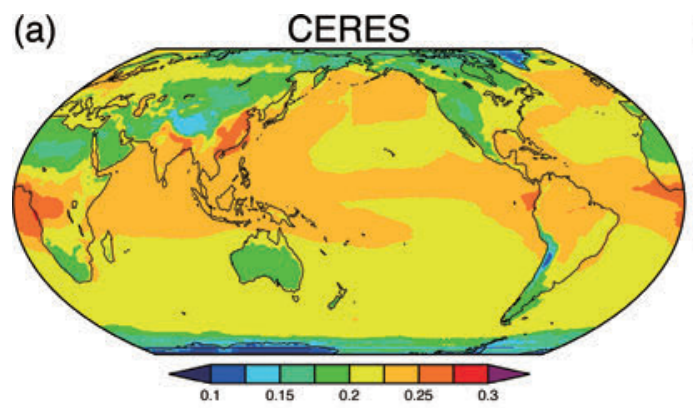

(c)

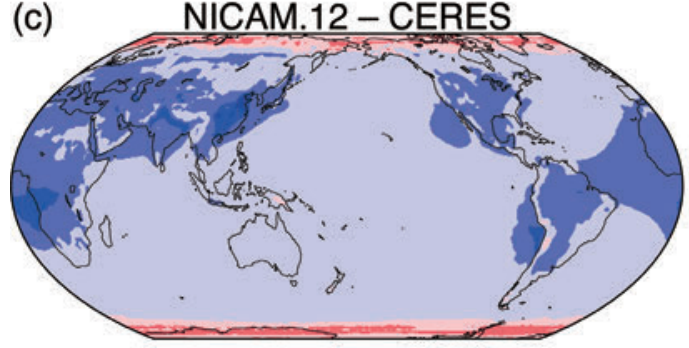

(e)

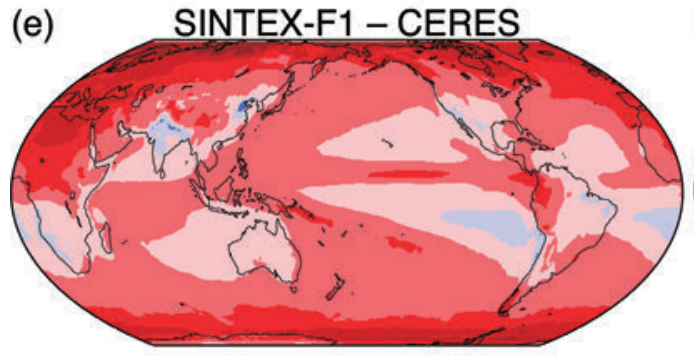

where $P_{s f c}$ is surface pressure, $t$ is the time, and $\theta$ is the latitude. LDR24 $\geqq 1 \mathrm{hPa} \mathrm{hr}{ }^{-1}$ is defined as an explosive development. The monthly activity of explosive cyclones is estimated using the following expression;

$$
\begin{aligned}
\text { LDR24P1 } & =\frac{1}{n} \sum_{i=1}^{n} \sigma_{1}(t=i) \\
\sigma_{1} & =\left\{\begin{array}{lr}
\text { LDR24, } & \text { if } \mathrm{LDR}_{24} \geq 1 \mathrm{hPa} \mathrm{h}^{-1} \\
0, & \text { otherwise }
\end{array},\right.
\end{aligned}
$$

where $n$ is the number of time steps in the month. In the present study, 6-hourly outputs of surface pressure are used. Unfortunately, SINTEX-F1 is not considered because it has no 6-hourly outputs. As a reference, LDR24P1 is also assessed using Japanese 55-year Reanalysis using
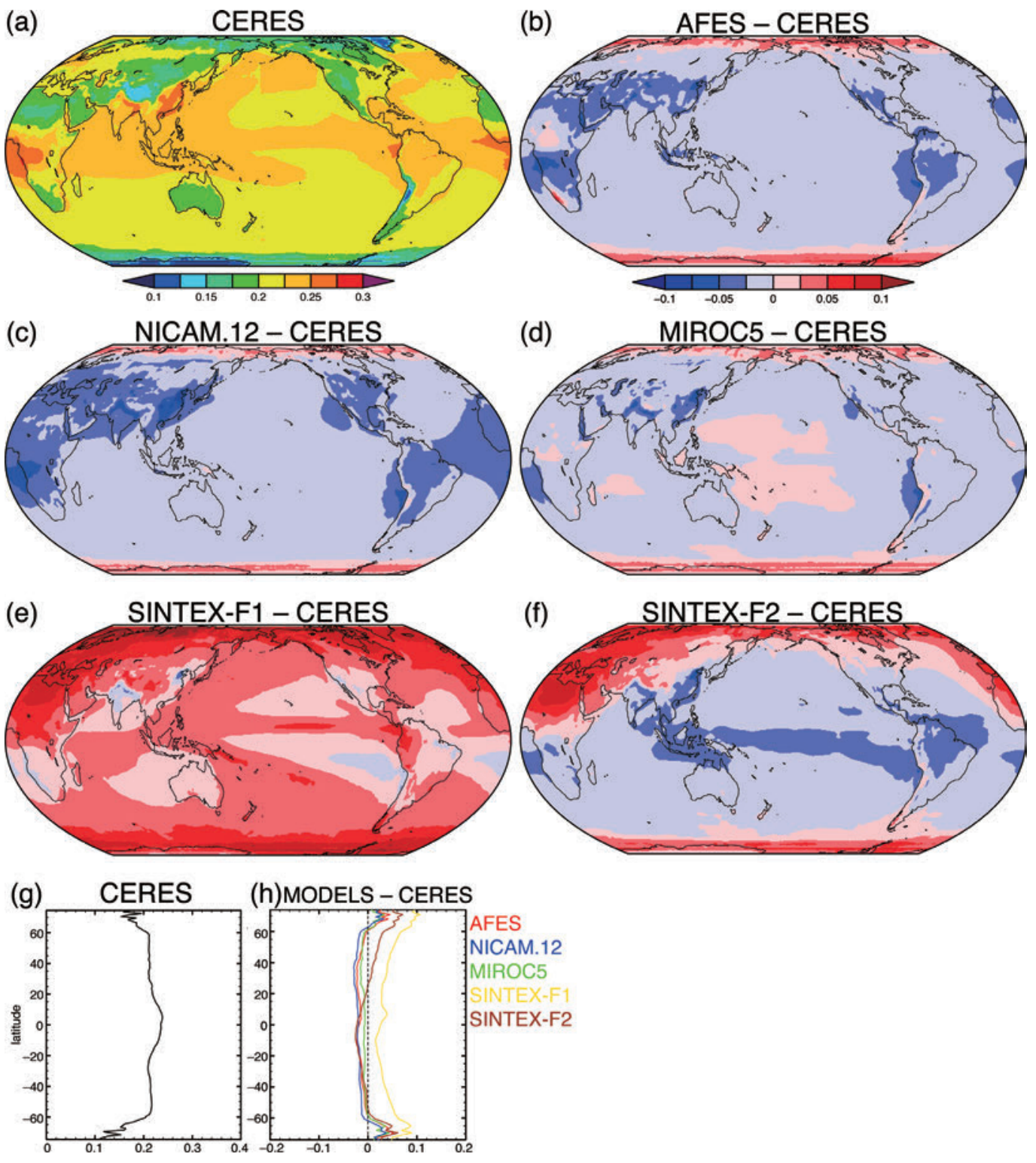

Fig. 6. Same as Fig. 5 but for atmospheric SW absorption rate. 
conventional data only (JRA-55C, Kobayashi et al. 2014), which is more homogeneous dataset over a long period because it is unaffected by changes in historical satellite observing systems.

Figure 7 shows LDR24P1 in January averaged from 1982 to 2001. In JRA-55C, LDR24P1 has a peak around $165^{\circ} \mathrm{E}, 42^{\circ} \mathrm{N}$ with $3.5 \mathrm{hPa}$ day $^{-1}$. AFES shows the strongest activity among the models and JRA-55C, although the distribution is similar to that of JRA-55C. MIROC5 shows the weakest activity among the models. SINTEX-F2 shows medium activity between AFES and MIROC5. These results are consistent with the results of Willison et al. (2013), i.e., that higher horizontal resolutions result in stronger explosive development. However, NICAM.12 shows weaker activity than SINTEX-F2 and AFES, despite NICAM.12 having the highest horizontal resolutions among the models. In addition, along the south coast of Japan, LDR24P1 shows weaker activity than the other models and JRA-55C.
The relative locations of the jet stream in the upper troposphere and the baroclinic zone in the lower troposphere can explain the activity differences among the models. Figure 8 shows zonal wind at $300 \mathrm{hPa}$ and the horizontal gradient of equivalent potential temperature at $850 \mathrm{hPa}$. In JRA-55C, the upper jet and baroclinicity are strong over the East China Sea and the Kuroshio and Kuroshio Extension. The models (except for NICAM.12 in which the baroclinic zone is not represented) show similar baroclinic zone distributions to that of JRA-55C.

The cold SST bias in NICAM.12 (see upper-right panel of Fig. A1 in Kodama et al. 2015) causes weak baroclinicity along the southern coast of Japan. Figure 9 shows the total surface turbulent heat flux. In NICAM.12, the flux over the Kuroshio and Kuroshio Extension is the weakest among the models and JRA-55C because setting the slab ocean model with a 7-day nudging relaxation time and 15-m depth cannot represent the horizontal heat advection
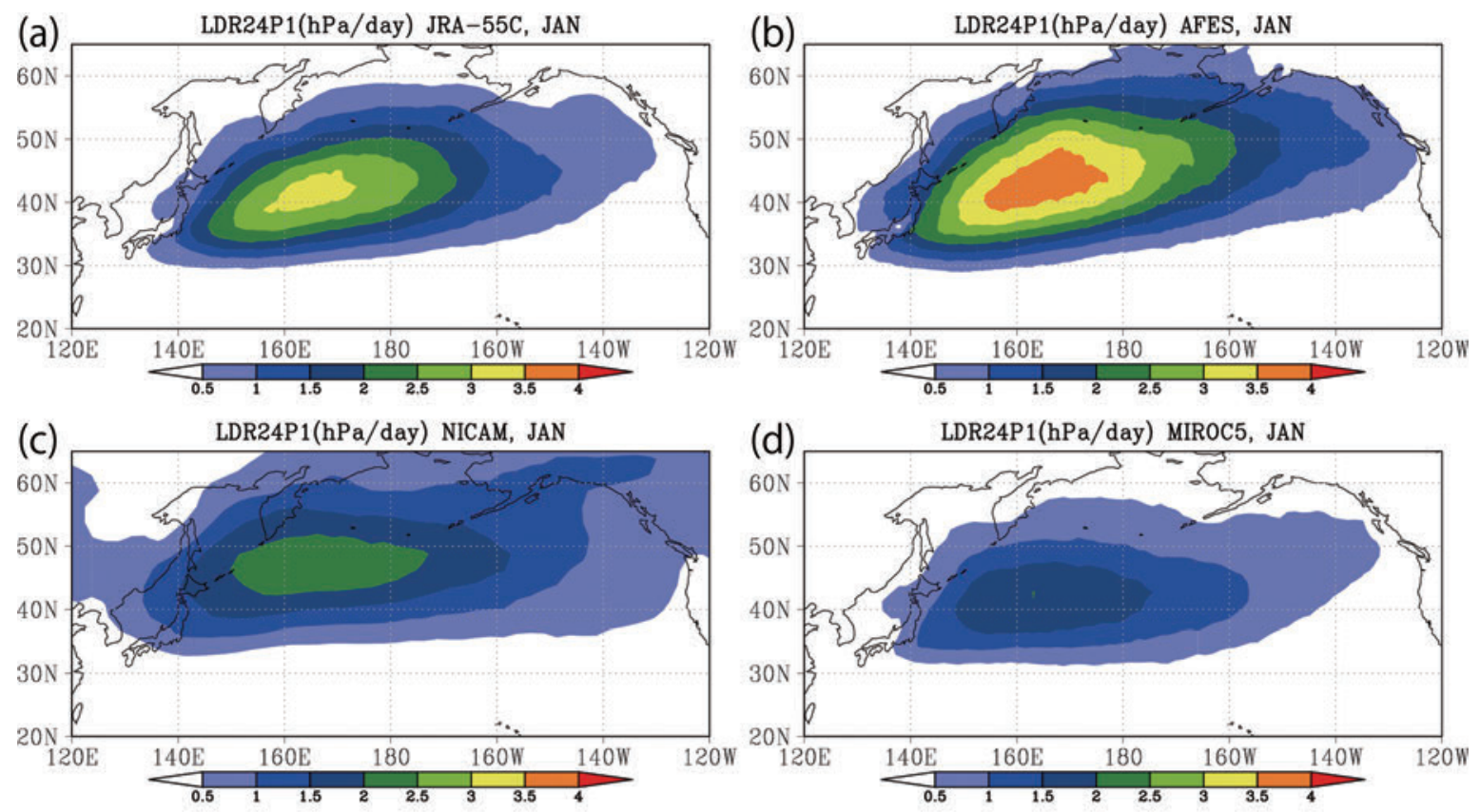

(e)

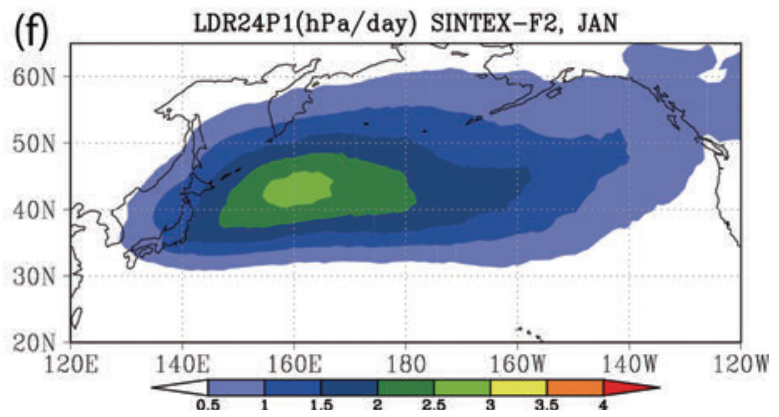

Fig. 7. Climatology of LDR24P1 in January $\left(\mathrm{hPa} \mathrm{day}^{-1}\right.$ ). (a) JRA-55C, (b) AFES, (c) NICAM.12, (d) MIROC5, (e) SINTEX-F1 (no data), and (f) SINTEX-F2. 
by the Kuroshio and Kuroshio Extension. SINTEX-F1 and SINTEX-F2, which use a shorter nudging relaxation time than does NICAM.12, present realistic distributions of SST and surface fluxes. These results are consistent with those of Kuwano-Yoshida and Minobe (2017), i.e., that the surface heat flux from the Kuroshio and Kuroshio Extension is important in representing the explosive cyclone activity in the Northwestern Pacific as well as the horizontal resolution.

\subsection{Rainfall variability related to interannual climate variations}

Unlike numerical weather prediction, numerical seasonal climate prediction presents challenges, particularly in the extratropics. The pioneering work by Bjerknes (1964; 1969) showed that the potential source of seasonal climate predictability is mostly related to air-sea coupled phenomena in the tropics and their teleconnection to the extratropics. It is well known that extratropical atmospheric variability is not primarily driven by local oceanic variability (as it is in the tropics). Therefore, it is crucial to capture the atmospheric response of basin-scale air-sea coupled climate phenomena in the tropics such as the ENSO and IOD, both of which are dominant modes of interannual variability and have enormous impact on the global climate (see Yamagata et al. 2016 for a recent review).

\subsubsection{ENSO}

First, we focus on horizontal maps of the correlation coefficients between the interannual variations in rainfall and the Niño3.4 index. The Niño3.4 index is one of the most commonly used indices for ENSO and is defined as the SST anomalies averaged over the domain $170^{\circ} \mathrm{E}-$ $120^{\circ} \mathrm{W}, 5^{\circ} \mathrm{S}-5^{\circ} \mathrm{N}$. Figure 10 shows the correlation map in January, when the ENSO events are most mature. El Niño events bring heavy rainfall over the central/eastern tropical Pacific and less rainfall to the west of the Philippines
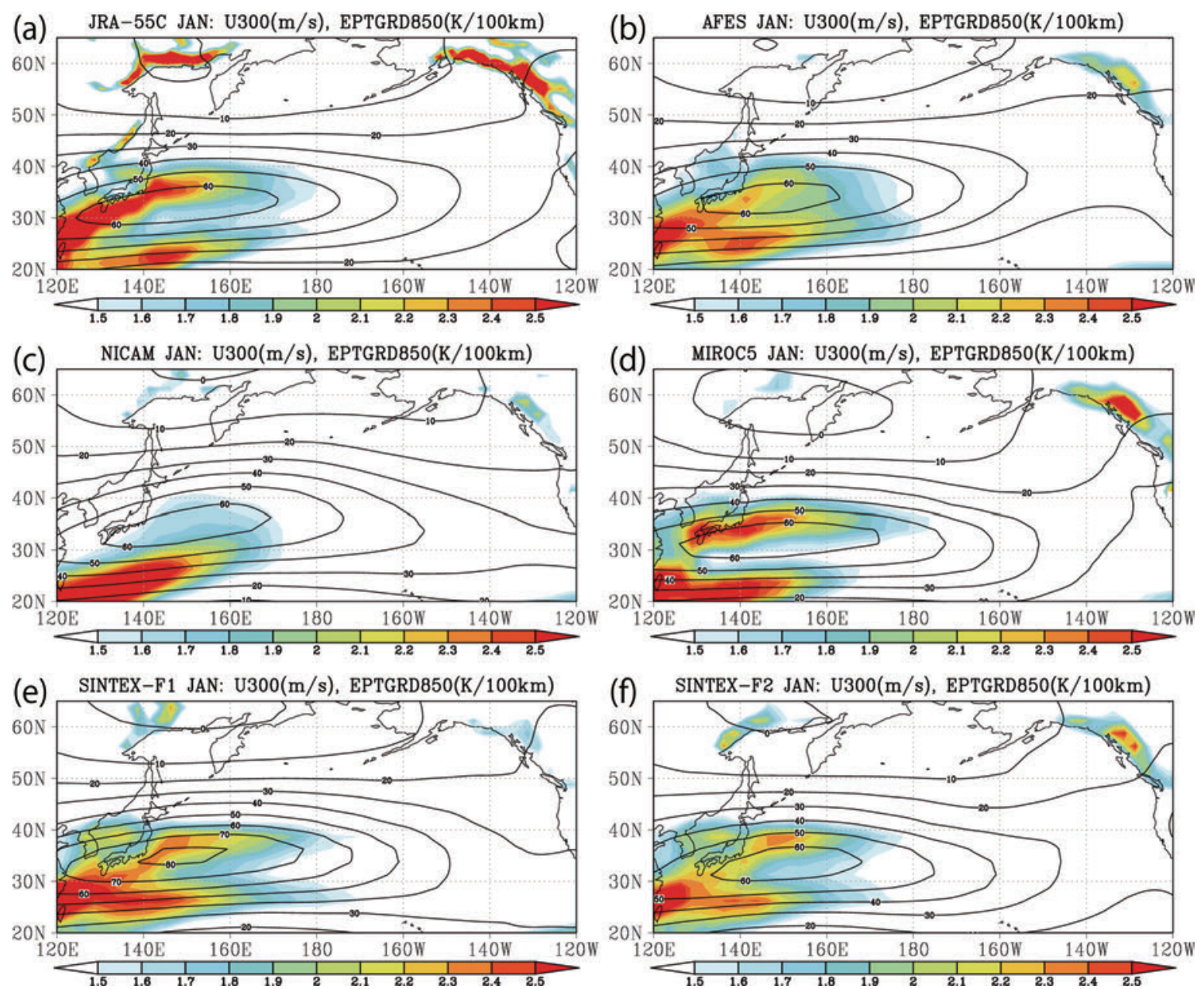

Fig. 8. Climatology of zonal wind at $300 \mathrm{hPa}\left(\mathrm{m} \mathrm{s}^{-1}\right.$; contours) and horizontal gradient magnitude of equivalent potential temperature at $850 \mathrm{hPa}$ (K $100 \mathrm{~km}^{-1}$; shading) in January. (a) JRA-55C, (b) AFES, (c) NICAM.12, (d) MIROC5, (e) SINTEX-F1, and (f) SINTEX-F2. 
and the Maritime Continent. As associated with El Niño (La Niña), the wetter (drier) than normal conditions over the central/eastern tropical Pacific are well captured by all models. The negative correlation over northern South America is also well captured by all models. These features of the JMIP models are consistent with the results of the AMIP runs from CMIP3 and CMIP5 (Langenbrunner and Neelin 2013). Although the observations show drier (wetter) than normal conditions over the Maritime Continent, all models simulate the opposite condition over most of the area. This failure is again similar to the results of the AMIP runs from CMIP3 and CMIP5 (Langenbrunner and Neelin 2013). There is some discrepancy among the JMIP models in relation to convection off the east of the Philippines, which may be the origin of teleconnection patterns having a potential impact on the East Asian winter climate, including
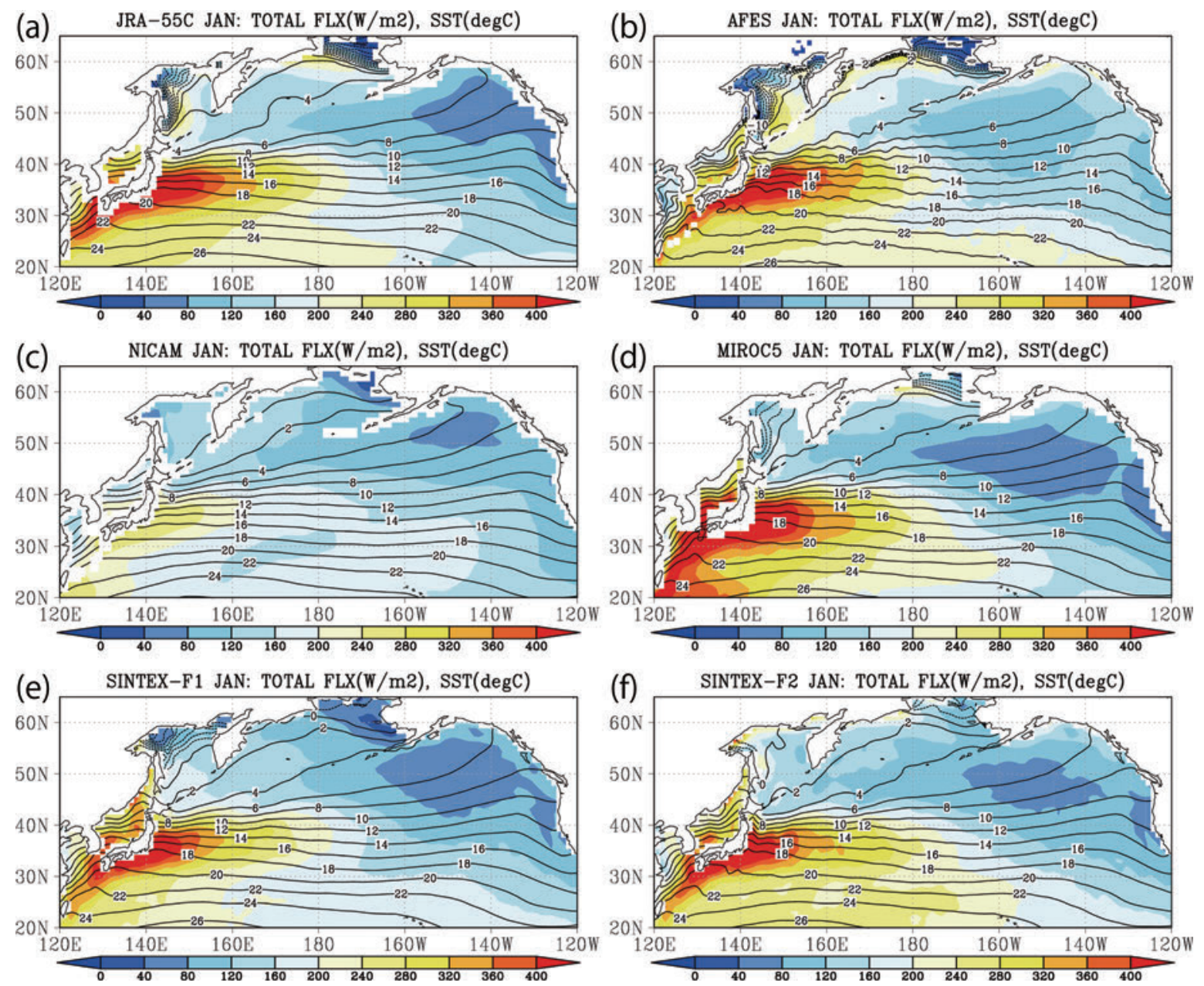

Fig. 9. Climatology of surface turbulent heat flux ( $\mathrm{W} \mathrm{m}^{-2}$; shading) and SST $\left({ }^{\circ} \mathrm{C}\right.$; contours). (a) JRA-55C, (b) AFES, (c) NICAM.12, (d) MIROC5, (e) SINTEX-F1, and (f) SINTEX-F2.

Table 6. (a) Regional average off the east of the Philippines $\left(120^{\circ}-160^{\circ} \mathrm{E}\right.$, Eq. $\left.-20^{\circ} \mathrm{N}\right)$ of the correlation coefficients in January between the interannual variations in rainfall and the Niño3.4 index. (b, c, d) Same as (a), but for October with the DMI for (b) the southern part of the western pole of the IOD $\left(50^{\circ}-70^{\circ} \mathrm{E}, 10^{\circ} \mathrm{S}-\mathrm{Eq}.\right)$, (c) the Middle East $\left(40^{\circ}-80^{\circ} \mathrm{E}, 20^{\circ}-40^{\circ} \mathrm{N}\right)$, and (d) eastern Australia $\left(140^{\circ}-155^{\circ} \mathrm{E}, 40^{\circ}-10^{\circ} \mathrm{S}\right)$.

\begin{tabular}{|l|c|c|c|c|}
\hline & $\begin{array}{l}\text { (a) Off the east of the } \\
\text { Philippines }\left(120^{\circ}-160^{\circ} \mathrm{E},\right. \\
\left.\text { Eq. }-20^{\circ} \mathrm{N}\right)\end{array}$ & $\begin{array}{l}\text { (b) Southern part of the } \\
\text { western pole of the IOD } \\
\left(50^{\circ}-70^{\circ} \mathrm{E}, 10^{\circ} \mathrm{S}-\mathrm{Eq} .\right)\end{array}$ & $\begin{array}{l}\text { (c) Middle East } \\
\left(40^{\circ}-80^{\circ} \mathrm{E}, 20^{\circ}-40^{\circ} \mathrm{N}\right)\end{array}$ & $\begin{array}{l}\text { (d) Eastern Australia } \\
\left(140^{\circ}-155^{\circ} \mathrm{E}, 40^{\circ}-10^{\circ} \mathrm{S}\right)\end{array}$ \\
\hline Obs. & -0.54 & 0.46 & 0.41 & -0.25 \\
\hline AFES & -0.32 & 0.28 & -0.049 & -0.23 \\
\hline NICAM.12 & -0.43 & -0.045 & -0.061 & -0.068 \\
\hline MIROC5 & -0.18 & 0.091 & 0.24 & -0.19 \\
\hline SINTEX-F1 & -0.45 & 0.27 & 0.040 & -0.31 \\
\hline SINTEX-F2 & -0.45 & 0.38 & 0.31 \\
\hline
\end{tabular}


Japan (Wang et al. 2000; Watanabe and Jin 2003). Therefore, its skillful simulation is crucial in predicting boreal winter conditions in East Asia. As shown in Table 6a, the drier (wetter) than normal conditions to the east of the Philippines associated with El Niño (La Niña) are well captured by SINTEX-F1, SINTEX-F2, and NICAM.12, whereas they are slightly underestimated by AFES and MIROC5. This may be party due to the similarities for excesses of tropical North and South Pacific precipitation in AFES and MIROC5 as highlighted in Fig. 2.

\subsubsection{IOD}

Next, we focus on the IOD mode. The IOD is normally characterized by dipole-type SST anomalies: cooling/warming of SSTs in the eastern/western tropical Indian Ocean as the positive event, and the reversed sign as the negative event. Associated with these SST anomalies, the convective region that is usually situated over the eastern Indian Ocean warm pool shifts to the west, leading to heavy rainfall over East Africa and severe droughts over the Indonesian region. Figure 11 is same as Fig. 10, but for October with the IOD Mode index (DMI), which is defined as the SST anomaly difference between

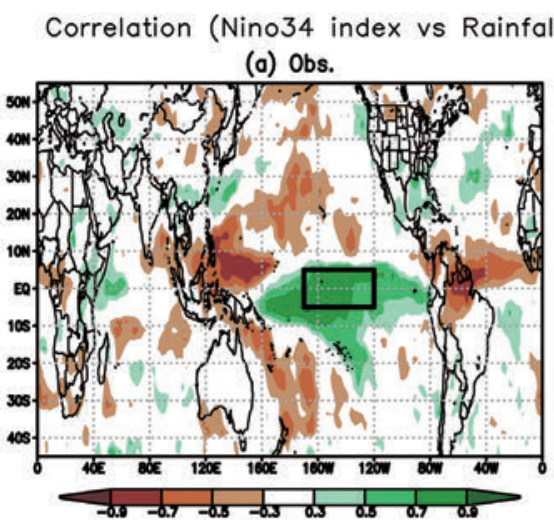

(c) NICAM.12

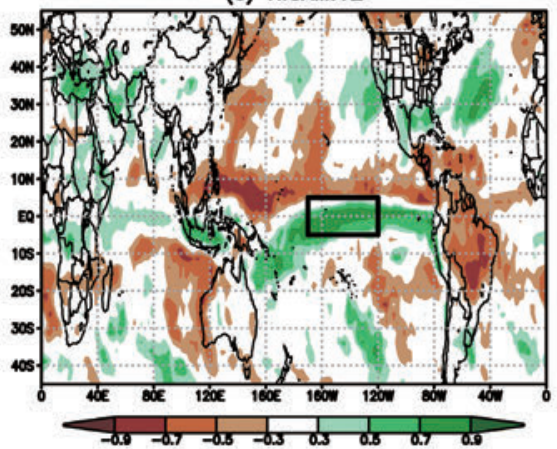

(e) SINTEX-F1

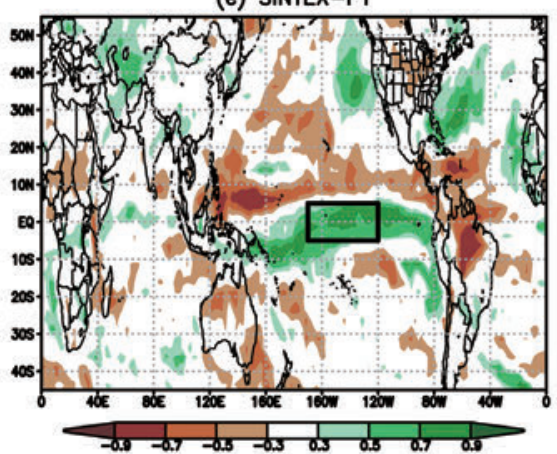

(b) AFES

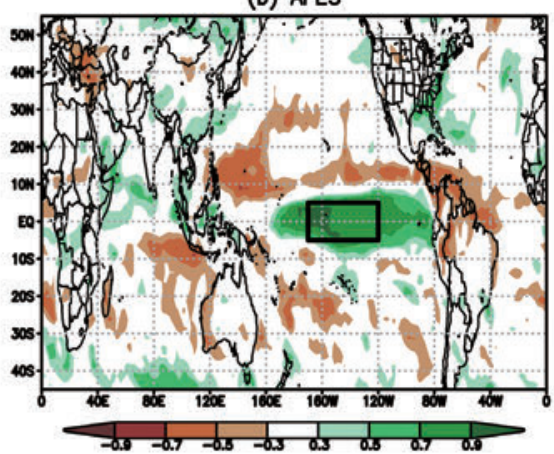

(d) MIROC5

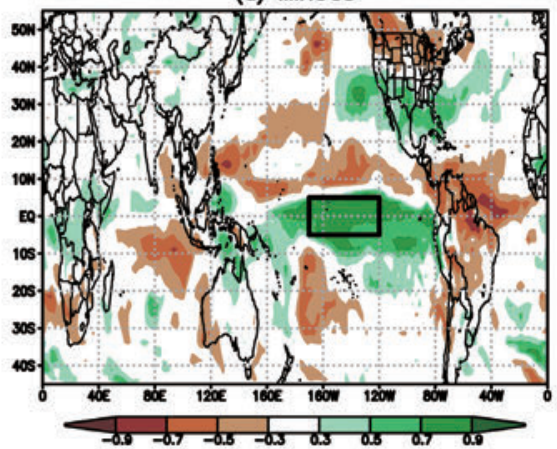

(f) SINTEX-F2

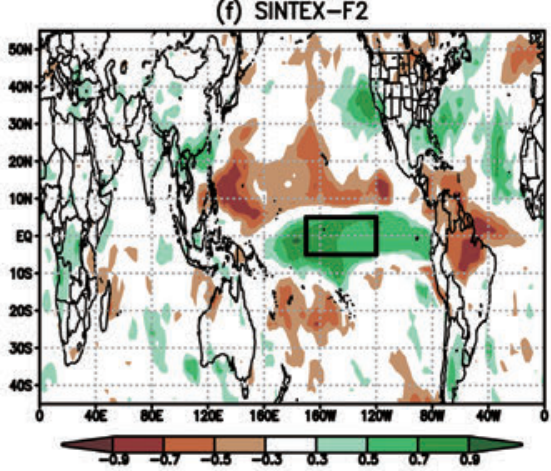

Fig. 10. (a) Horizontal maps of correlation coefficients between the Niño3.4 index and interannual variations of rainfall in January. The analysis period is 1983-2000. The Niño3.4 is from OISSTv2, and the rainfall is from GPCP (version 2.3). The Niño3.4 region is shown by a black rectangle. (b, c, d, e, f) Same as (a), but for rainfall simulated by AFES, NICAM.12, MIROC5, SINTEX-F1, and SINTEX-F2, respectively. 
the western pole off East Africa $\left(50^{\circ} \mathrm{E}-70^{\circ} \mathrm{E}, 10^{\circ} \mathrm{S}-10^{\circ} \mathrm{N}\right)$ and the eastern pole off Sumatra $\left(90^{\circ} \mathrm{E}-110^{\circ} \mathrm{E}, 10^{\circ} \mathrm{S}-\mathrm{Eq}\right)$ (Saji et al. 1999). Negative correlation coefficients for the eastern pole and the Maritime Continent, indicating the drier (wetter) than normal conditions associated with the anomalous cooling (warming) of SSTs, is well captured (but slightly underestimated) by all models. However, none of the models successfully simulate the broad domain of positive correlation centered on the western pole of the IOD. Namely, the wetter (drier) than normal conditions associated with the anomalous warming (cooling) of SSTs in the western pole during the positive (negative) event are underestimated by all models. The positive correlation over the southern part of the western pole is better simulated by AFES, SINTEX-F1, and SINTEX-F2 relative to NICAM.12 and MIROC5 (Table 6b). The positive correlation coefficients over the Middle East are captured by SINTEX-F2 and MIROC5, whereas AFES, NICAM.12, and SINTEX-F1 underestimated these coefficients (Table 6c). The negative correlation over eastern Australia is well captured by SINTEX-F2 and AFES but not by the other models (Table 6d). This is very important for Australian winter wheat yields (Yuan and Yamagata 2015). Overall, SINTEXF2 best captures the correlation distribution associated with


Fig. 11. Same as Fig. 10, but for the Indian Ocean Dipole Mode index (DMI), which is defined by Saji et al. (1999) as the SST anomaly difference between the western pole off East Africa $\left(50^{\circ} \mathrm{E}-70^{\circ} \mathrm{E}, 10^{\circ} \mathrm{S}-10^{\circ} \mathrm{N}\right)$ and the eastern pole off Sumatra $\left(90^{\circ} \mathrm{E}-110^{\circ} \mathrm{E}, 10^{\circ} \mathrm{S}-\mathrm{Eq}\right)$. The analysis month is October. 
the IOD. This may be partly due to that the east-west dipole structure of a precipitation bias over the Indian Ocean in the mean state is small with SINTEX-F2, although the precipitation over ocean is largely overestimated relative to the other models (Fig. 2).

In this subsection, we have shown that the tropical rainfall pattern associated with ENSO is relatively well captured by all models. The strong agreement among the models may provide a good predictor for ENSO teleconnection (Langenbrunner and Neelin 2013). However, simulating the IOD's response remains a challenge for all models. As far as we know, there is no study investigating IOD teleconnection using the AMIP runs from CMIP3 and CMIP5. More effort is necessary to improve the remote responses of the simulated convection to the IOD.

\subsection{Asian monsoon}

Monsoons are a basic variability on the Earth and are associated with seasonal cycles and land-ocean distribution; therefore, they are characterized by strong regionality. The Asian summer monsoon has the largest horizontal scale and most significant impacts on world weather and climate. In fact, it provides a basic environment for tropical cyclone genesis in the western North Pacific (Holland 1995). Because of its regionality coupling with multi-scales and its multi-process nature (e.g., air-sea-land interactions), the accurate simulation and prediction of monsoons are still challenging even for the latest climate models (Sperber et al. 2013). In this subsection, we examine the climatology and interannual variability of the Asian summer monsoons in the five JMIP models to understand the commonality and diversity across aspects that are reproduced both poorly and relatively well. Here, we use all the available data for each JMIP model: 1979-2008 for MIROC5, NICAM.12, and JRA-55, 1982-2001 for AFES, 1982-2013 for SINTEX-F1, and 1982-2014 for SINTEXF2.

Figure 12 shows the June-September mean lower tropospheric zonal wind in the objective analysis (JRA-55) and in the simulations. The intensification of the westerlies along the southern edge of the warm air mass over the Eurasian continent and its eastward seasonal extension is a typical feature of the Asian summer monsoon. The westerlies exhibit a peak over the western Indian Ocean and extend southeastward along the southern edge of the Pacific high over the central Pacific. All the models successfully simulate the westerlies over the tropical Indo-Pacific domain, although they have a tendency to overestimate the Pacific high. Close examination finds that the pattern of the wind field is better simulated in AFES and SINTEXF2, whereas the strength of the peak westerlies over the western Indian Ocean are excessive in AFES, MIROC5, and SINTEX-F2 (Figs. 12a, b, d, and f). In NICAM.12 and MIROC5, the axis of the peak westerlies shows a northward bias over the Indian subcontinent and the Bay of Bengal (Fig. 12c, 12d). In SINTEX-F1, the westerlies intrude farthest over the western Pacific along approximately $15^{\circ} \mathrm{N}$, with weak zonal contrast (Fig. 12e). This tendency is improved in SINTEX-F2 (Fig. 12f). NICAM.12 is distinct from the other models in that the meridional gradient of the Pacific high is very pronounced, yielding overestimation of trade wind $\left(10^{\circ} \mathrm{N}-20^{\circ} \mathrm{N}\right)$ and westerly jet $\left(40^{\circ} \mathrm{N}-60^{\circ} \mathrm{N}\right)$ over the central Pacific, and strong zonal confluence over the western North Pacific to the north of the Philippines (Fig. 12c)

Precipitation is another important parameter of the Asian summer monsoon. As a comparison with GPCP, Fig. 13 shows the June-September mean precipitation corresponding to Fig. 12. At a glance, the precipitation pattern is poorly reproduced compared with the flow pattern, implying difficulties in properly simulating moist processes, especially the nonlinear feedback between convection and circulation; intensification of vertical and horizontal circulation by latent heat release and invigoration of moist convection by the intensified circulation through enhancement of moisture convergence. This feedback should largely depend on the model physics, such as convective parameterizations. None of the models successfully capture the precipitation peak to the southeast of the Philippines $\left(120^{\circ} \mathrm{E}-150^{\circ} \mathrm{E}, 5^{\circ} \mathrm{N}-20^{\circ} \mathrm{N}\right.$; Fig. $\left.13 \mathrm{a}\right)$, which is closely related to tropical cyclogenesis in the western North Pacific. A common bias in the domain-mean overestimation of the precipitation amount is also noticeable. The tendencies (biases) in the individual models are generally consistent with the flow tendencies (biases) in Fig. 12. In AFES and MIROC5, precipitation peaks are formed over the Arabian Sea and the Bay of Bengal (Fig. 13b, 13d), reflecting the strong westerlies (Fig. 12b, 12d). Compared with GPCP, precipitation peaks over India are displaced northward in NICAM.12 and MIROC5 (Fig. 13a, 13c 13d). SINTEX-F1 produces a large amount of precipitation to the east of the Philippines (Fig. 13e), which is collocated with the intrusion 
of westerlies in that region (Fig. 12e). SINTEX-F2 produces a realistic precipitation pattern over the Indian Ocean and equatorial central Pacific, albeit with the greatest excess in terms of total amount (Fig. 13f). In all of the simulations, precipitation along the southern edge of the Pacific high partly accounts for the excessive precipitation amount over the domain.

Next, the seasonal march of the Asian monsoon is investigated by monsoon indices based on the $850-\mathrm{hPa}$ zonal wind (Wang et al. 2001), i.e., the western North Pacific monsoon index (WNPMI), which is defined as the difference between the average for $100^{\circ} \mathrm{E}-130^{\circ} \mathrm{E}, 5^{\circ} \mathrm{E}-$ $15^{\circ} \mathrm{N}$ and the average for $110^{\circ} \mathrm{E}-140^{\circ} \mathrm{E}, 20^{\circ} \mathrm{N}-30^{\circ} \mathrm{N}$; and the Indian monsoon index (IMI), which is defined as the difference between the average for $40^{\circ} \mathrm{E}-80^{\circ} \mathrm{E}, 5^{\circ} \mathrm{N}-15^{\circ} \mathrm{N}$ and the average for $70^{\circ} \mathrm{E}-90^{\circ} \mathrm{E}, 20^{\circ} \mathrm{N}-30^{\circ} \mathrm{N}$ (green boxes in Fig. 12). These indices represent the major sub-system of the Asian Monsoon. Figure 14 shows the annual cycle of the WNPMI and IMI as calculated from the climatological winds. The IMI sharply increases from April to May, its sign is reversed and it almost reaches its annual peak value in June. The IMI maintains its peak strength until August, and recedes thereafter (Fig. 14a). The sharp increase in early summer, namely, the onset of the monsoon, is successfully simulated in all the JMIP models. The difference in IMI strength among the models during the mature period (JuneAugust) is attributable to the biases in the flow pattern, as seen in Fig. 12. The WNPMI shows a more gradual increase during April-August, reversing its sign in June and reaching its peak intensity in August. NICAM.12 simulates (a)
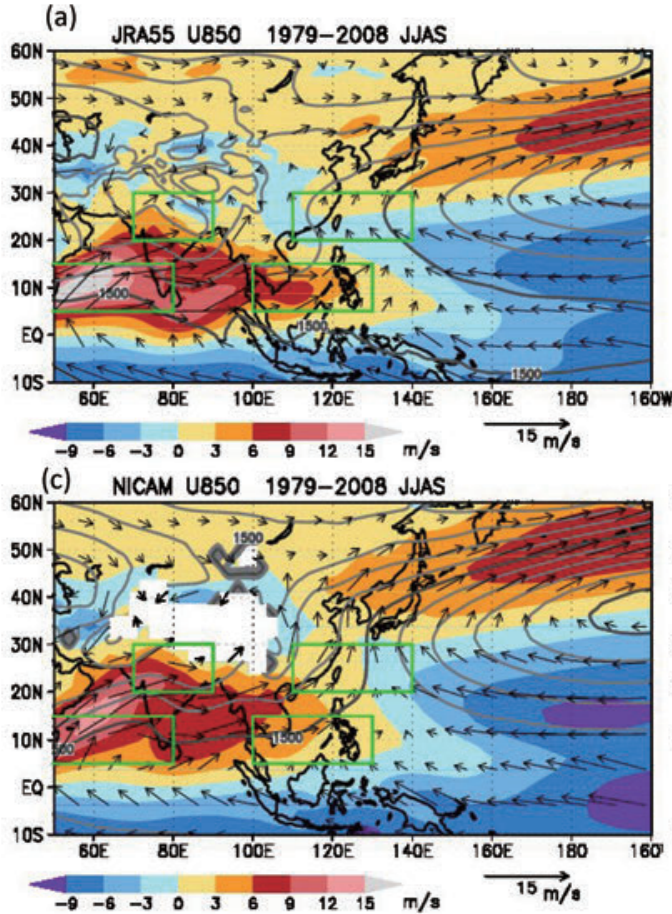

(e) SINTEX U850 1982-2013 JJAS

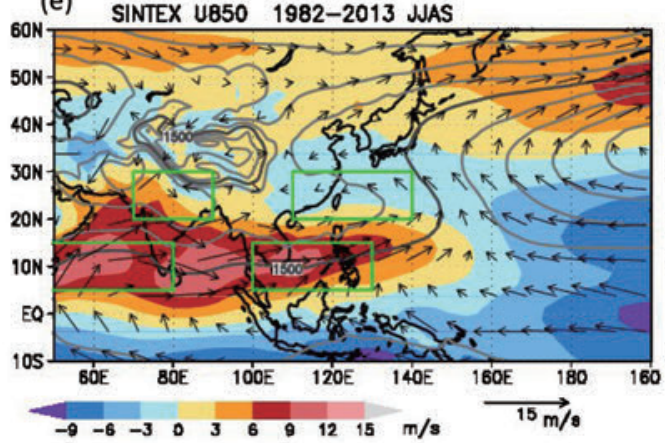

(b)
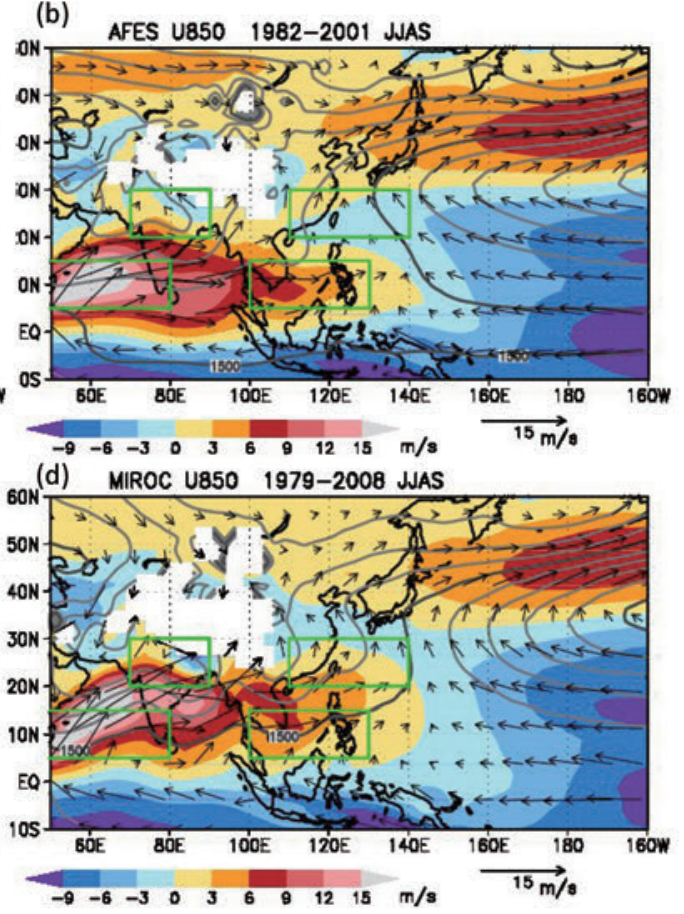

(f) SINTEX_F2 U850 1982-2014 JJAS

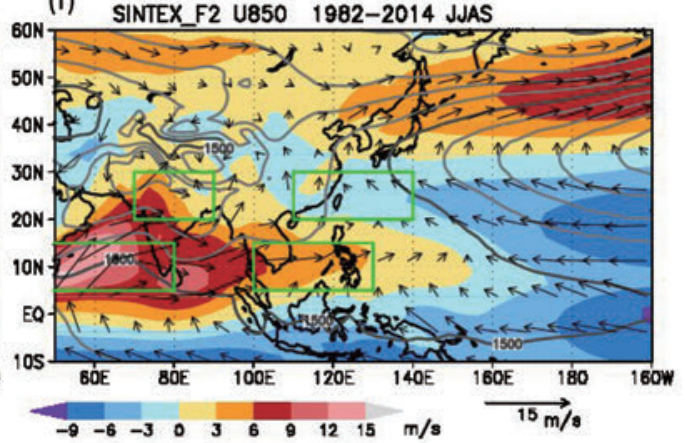

Fig. 12. Climatology of 850-hPa zonal wind (colors) and geopotential height (contours) averaged across June-September in (a) JRA-55, (b) AFES, (c) NICAM.12, (d) MIROC5, (e) SINTEX-F1, and (f) SINTEX-F2. The green boxes indicate the area considered for the monsoon indices. 
the evolution of the WNPMI (from winter to summer) relatively well, with a deficit in peak intensity due to the northward displacement of the westerly axis (Fig. 14b; Kodama et al. 2015). AFES, SINTEX- F1, and SINTEXF2 show earlier development of the western North Pacific monsoon in June, which is close to the onset of the Indian monsoon. The large WNPMI in SINTEX-F1 is associated with the robust westerlies in this domain (Fig. 12e), which become established earlier and are sustained longer than in the other models and in JRA-55. After June, this bias is reduced in SINTEX-F2, with the best performance occurring during the mature period of the summer monsoon (Fig. 14b). The strong performance of SINTEX-F2 is consistent with its good representation of the seasonal mean field (Fig. 12f). The failure of MIROC5 to simulate the seasonal cycle of WNPMI is attributed to the meridionally expanded pattern of the westerlies (Fig. 12d). Across the JMIP models (except for SINTEX-F1) and JRA-55, the seasonal cycle of the average 850-hPa zonal wind over the western North Pacific (Fig. 14c) shows good agreement. In summary, the basic aspects of the climatology of the Asian summer monsoon are reasonably well simulated in all the models in terms of the lower tropospheric circulation, both in relation to flow pattern and temporal evolution; however, there also exist individual biases that should be handled cautiously. As to the moist convection associated with the monsoon, the biases are far more severe and diverse, presumably reflecting the differences in physical parameterizations.

Finally, we present a few remarks on interannual variability and discuss the impact of SST forcing on the Asian summer monsoon. Figure 15 shows the time series of the WNPMI anomalies in each model. The correlation (a) GPCP PRCP 1979-2008 JJAS

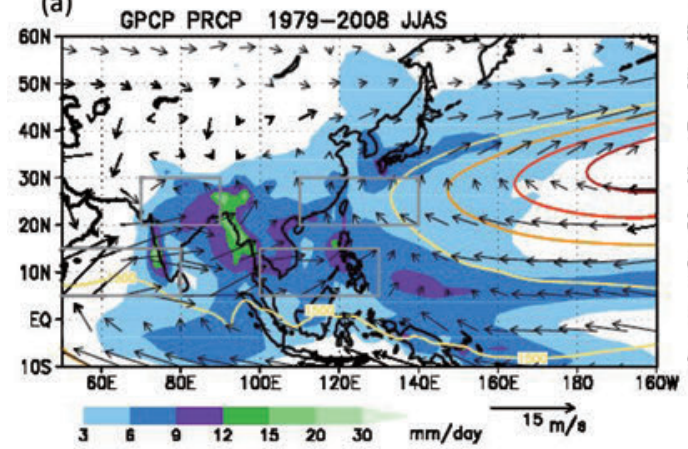

(c)

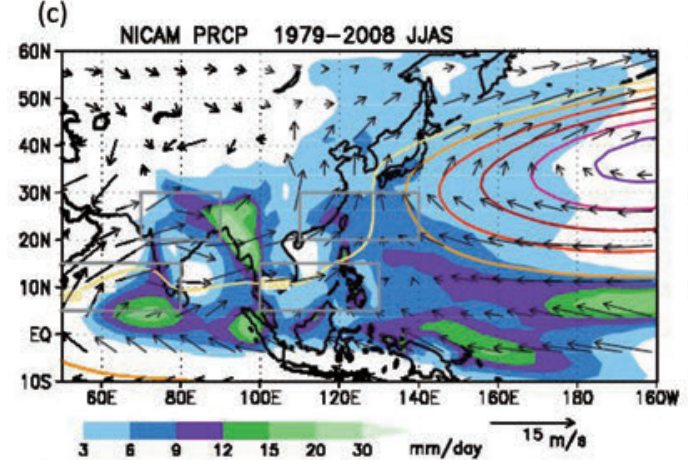

(e) SINTEX PRCP 1982-2013 JUAS

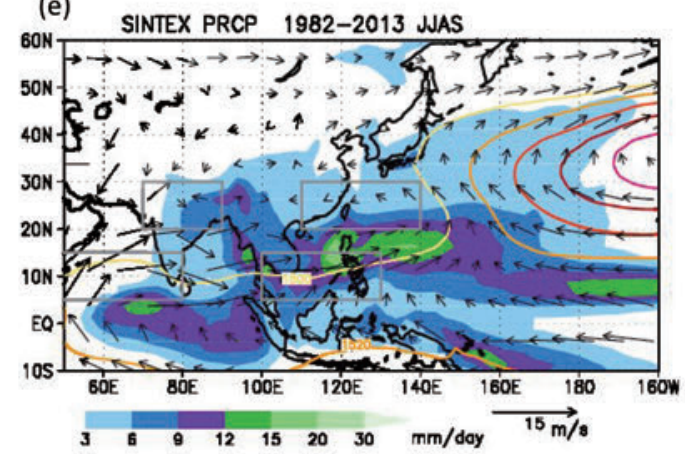

(b) AFES PRCP 1982-2001 JJAS

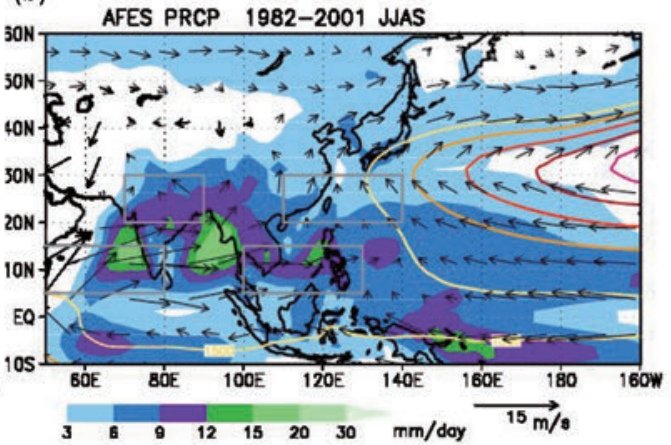

(d) MIROC PRCP 1979-2008 JJAS
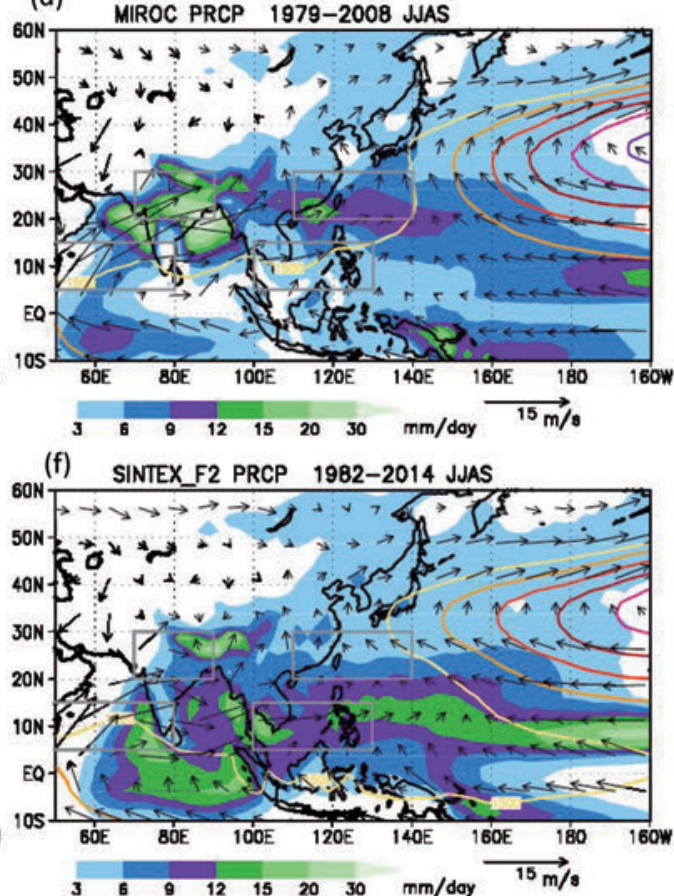

Fig. 13. Same as Fig. 12 but for precipitation rate (colors). GPCP precipitation is shown in (a). 
with the time series in JRA-55 does not seem to be strong, especially after 2000. However, in the years of low WNPMI (i.e., 1983, 1988, and 1998), almost all of the models show negative anomalies. These years correspond to the post El
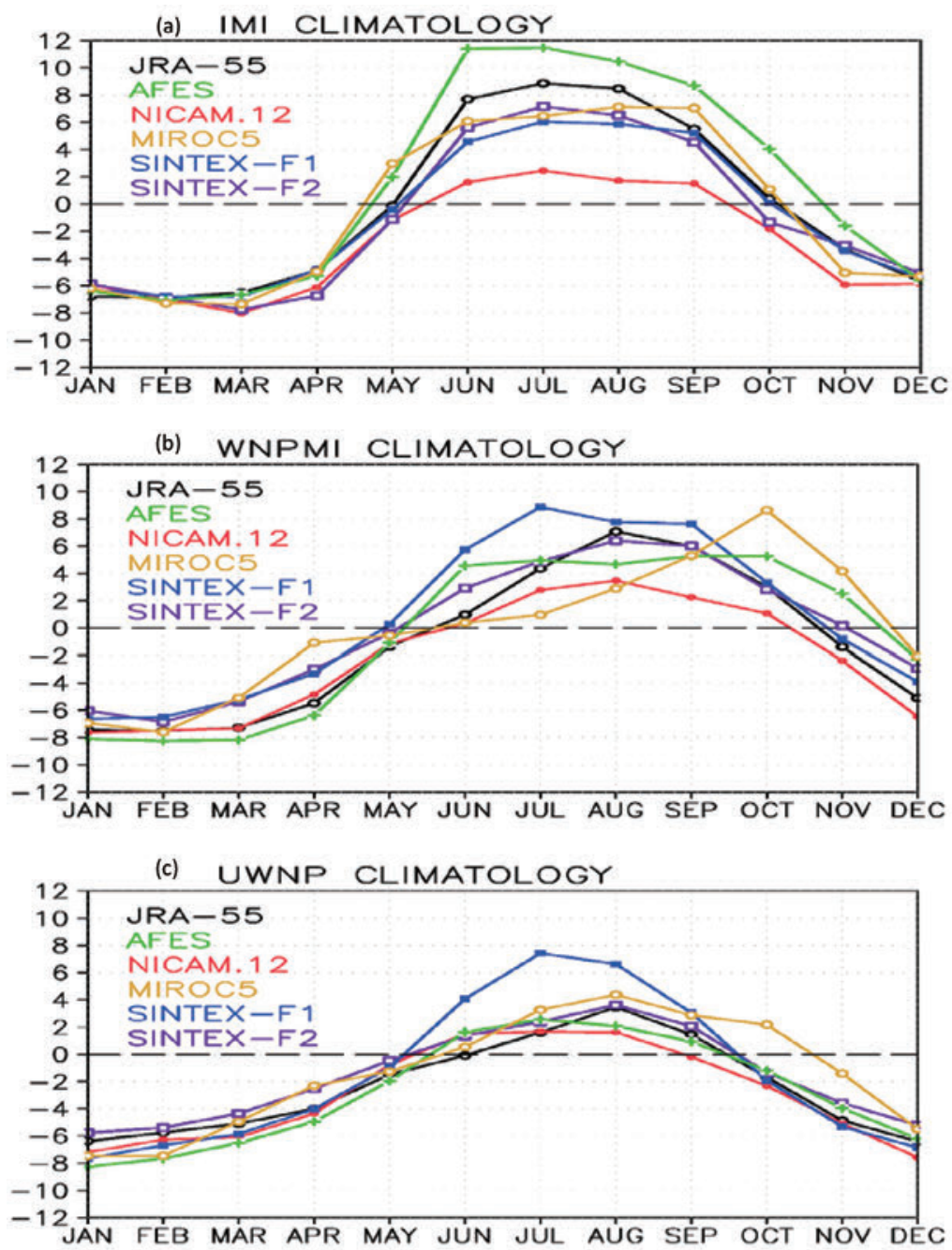

Fig. 14. Climatological annual cycle of the (a) Indian and (b) western North Pacific monsoon index (Wang et al. 2001), and (c) the 850-hPa zonal velocity averaged in the $110^{\circ} \mathrm{E}-140^{\circ} \mathrm{E}, 5^{\circ} \mathrm{N}-20^{\circ} \mathrm{N}$ domain.

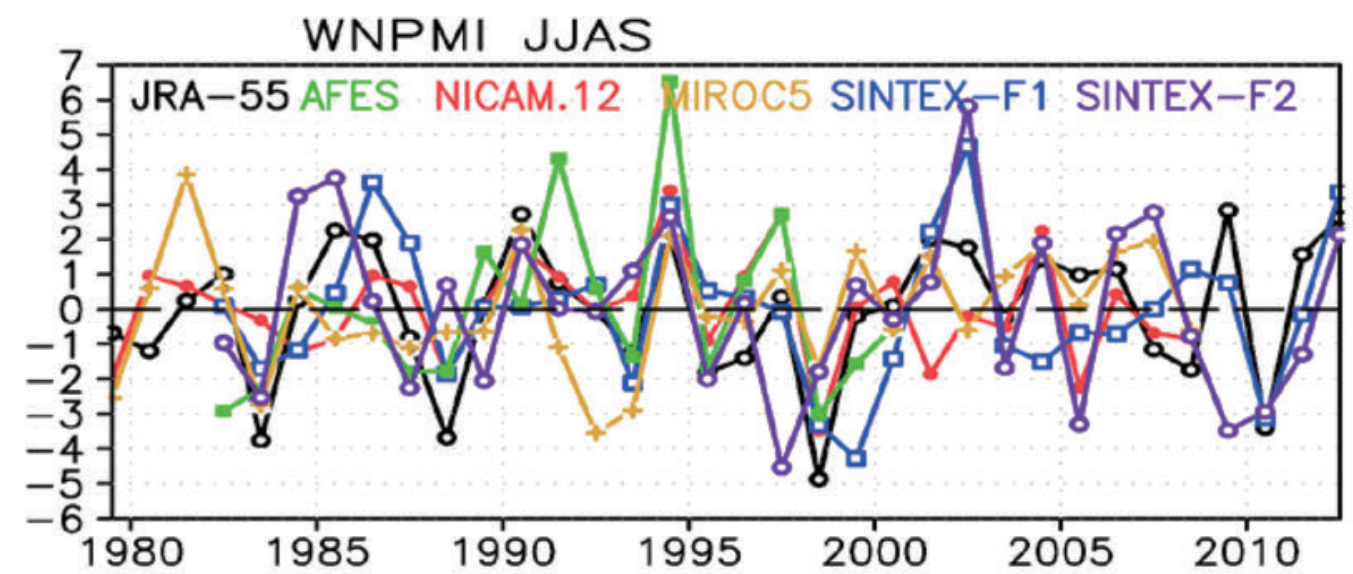

Fig. 15. Interannual variability of the western North Pacific monsoon index averaged over June-September. Anomalies from the climatology in each model are plotted. 
Niño summer. It is generally known that in these years the Indian Ocean tended to be warm and anticyclonic circulation anomalies appeared over the tropical western Pacific as an atmospheric response (Xie et al. 2009). In fact, the SST

(a)

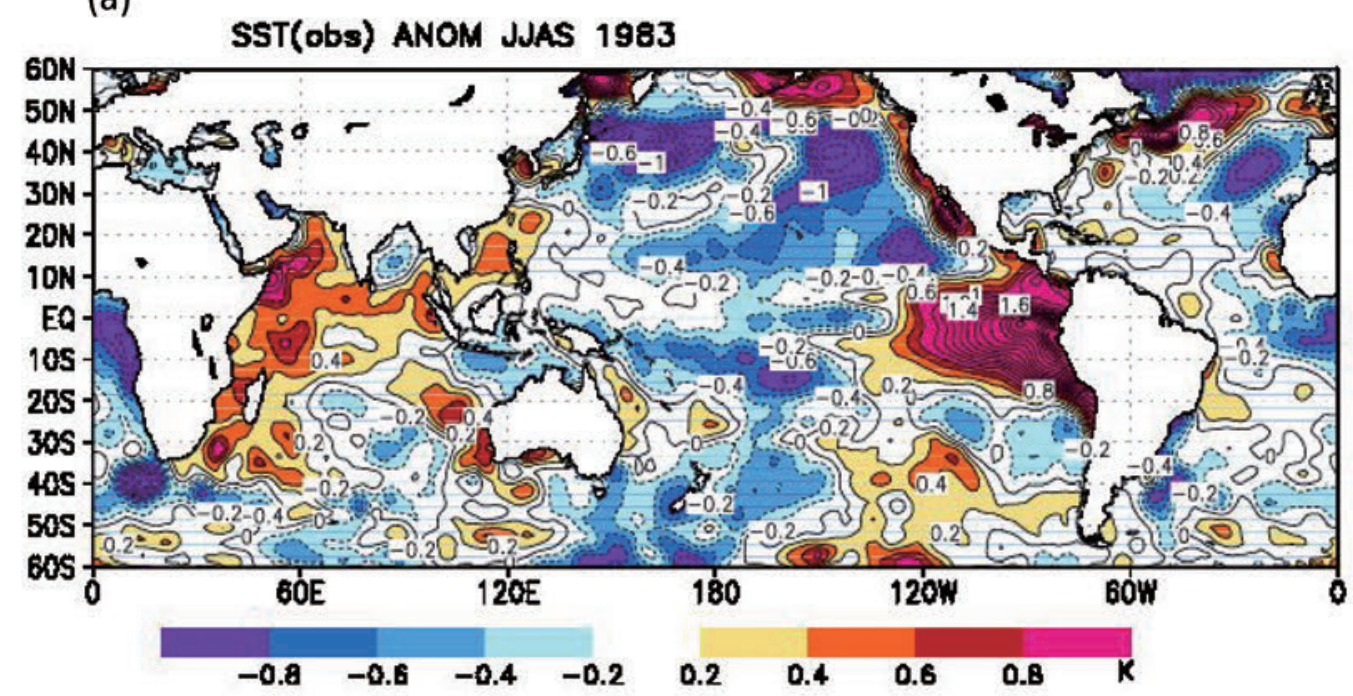

(b) SST(obs) ANOM JJAS 1998

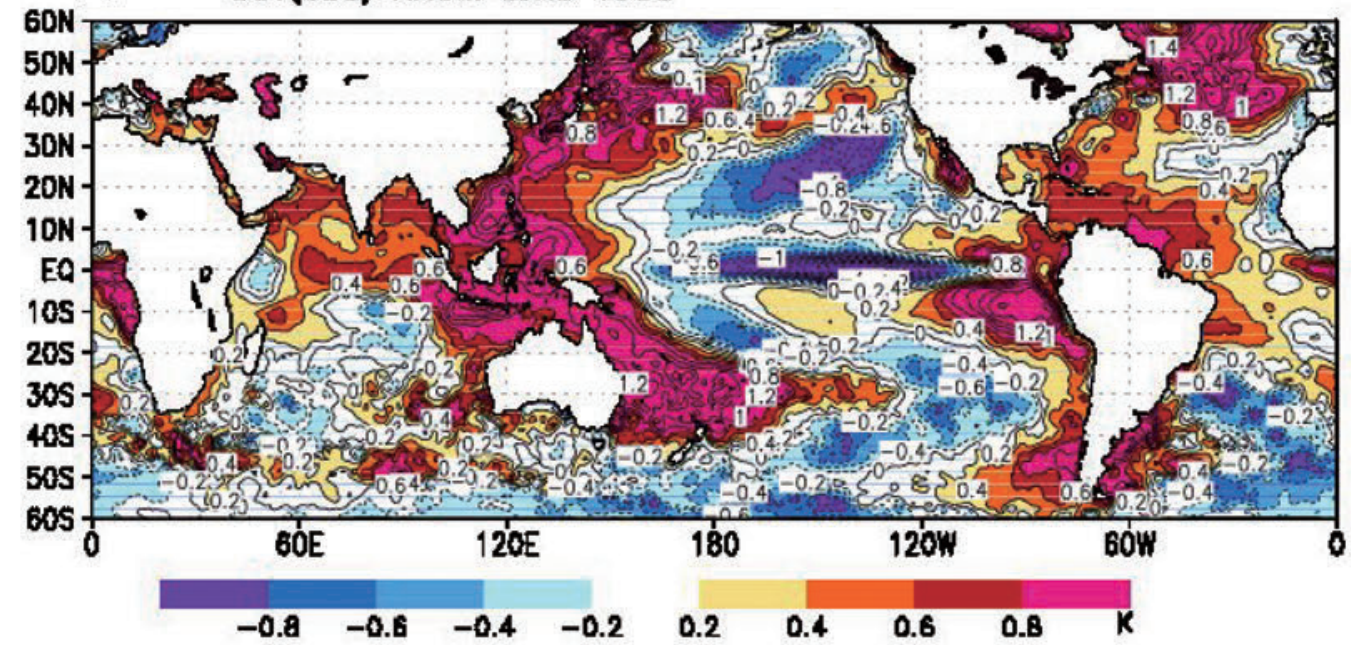

(c)

SST(obs) ANOM JJAS 1994

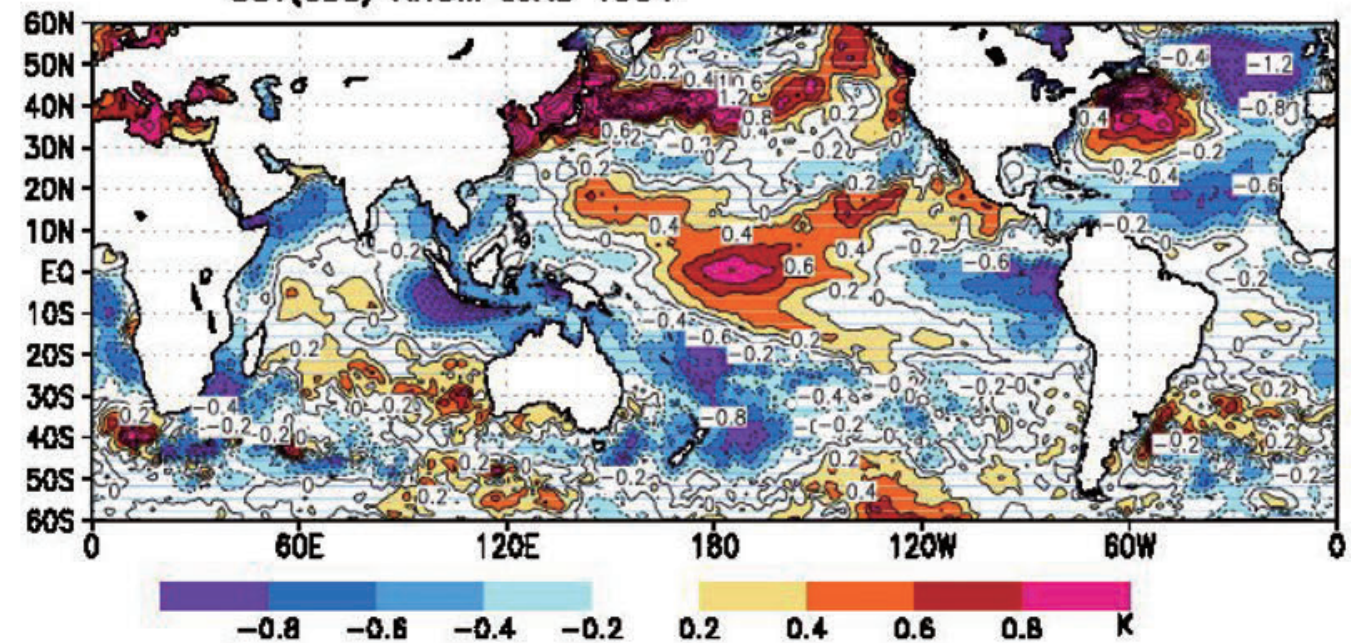

Fig. 16. Sea surface temperature anomalies averaged over June-September in NOAA OISST (1.0) in (a) 1983, (b) 1998, and (c) 1994. 
anomalies in these years (Fig. 16a, 16b) are positive over the northern Indian Ocean. In contrast, all of the models simulate the stronger WNPMI in 1994. In this year, the SST had a cold anomaly over the eastern Indian Ocean and a warm anomaly over the equatorial central Pacific (Fig. 16c), which may have enhanced cyclonic circulation over the tropical western Pacific under the influence of an extremely strong positive IOD event (Guan and Yamagata 2003; Saji et al. 1999) and positive Pacific meridional mode (Chiang and Vimont 2004). These results suggest control of local and remote SST forcing over the interannual variability of the monsoon circulation over the western North Pacific, but there is a fundamental limitation in the AMIP-type setup (Wang et al. 2005). Well-posed and systematic investigations are warranted to better understand and properly simulate the relationship between the Asian monsoon and SST forcing, where moist convection plays a key role.

\section{Summary and future perspective}

JMIP offers a first opportunity to systematically compare the climatology and variability simulated by the five AGCMs (AFES, MIROC5, NICAM.12, SINTEX-F1, and SINTEX-F2) developed and/or used in JAMSTEC. The outputs of the climate simulations are analyzed using subjectively chosen metrics, including climatological means of precipitation, the zonal mean basic state, radiation, explosive extratropical cyclones, and the Asian summer monsoon, and their variability associated with the ENSO and IOD mode. Although some or most of the dynamical and physical packages in the JMIP models have been developed independently, similar model biases are found among the models. In particular, AFES and MIROC5 have many similarities in terms of the simulated climate, e.g., precipitation pattern, zonal mean basic state, atmospheric shortwave absorption, Asian summer monsoon, and precipitation variability associated with the ENSO. This was noted despite the fact that the physics packages, i.e., cumulus convection, stratiform clouds, turbulent schemes, treatment of aerosols, and horizontal and vertical resolutions, are all different. Similarities are also found between SINTEX-F1 and SINTEX-F2. Although SINTEXF2 systematically overestimates mean precipitation, it better simulates the variability in precipitation associated with the ENSO and IOD mode than does SINTEX-
F1. In relation to the performance of the climatology, NICAM.12 tends to show differences from the other models, e.g., in the precipitation, explosive extratropical cyclones, and the Asian summer monsoon onset. Our analysis revealed the challenges faced by all the models in simulating climatology and the variability of the regional precipitation patterns, especially in the Asian monsoon regions. These challenges may be linked to the difficulties in simulating the teleconnection pattern by the ENSO and IOD mode around the Maritime Continent. In addition, large differences in atmospheric SW reflection are found among the models, which are likely related to cloud characteristics (amount and optical thickness). Understanding and improving these model biases are key issues for all the modeling groups. Note that the observed SST boundary conditions were directly imposed in AFES and MIROC5, whereas they were imposed via nudging techniques in NICAM.12, SINTEX-F1, and SINTEX-F2 (Table 1). As discussed in Section 4.3, the large difference between the observed and modeled SST in NICAM.12 leads to weaker simulated explosive extratropical cyclones. Meanwhile, SST nudging improves the distribution of tropical precipitation in NICAM.12 (Kodama et al. 2015), suggesting the importance of understanding atmosphereocean coupling when reconsidering the methodologies for imposing SST boundary conditions in an AGCM.

To some extent, the similarities and differences among the JMIP models overlap with those among the CMIP5 models. Both the CMIP5 and JMIP models (note that MIROC5 belongs to both CMIP and JMIP) tend to underestimate the low-level cloud fraction (Wang and $\mathrm{Su} 2013$ ) and simulate excessive tropical precipitation and a double ITCZ (Hirota and Takayabu 2013). They also struggle to simulate climatology and the seasonal march and interannual variability of the Asian summer monsoon (Sperber et al. 2013). In this context, JMIP can be considered a simple and in-depth version of CMIP with which to investigate the mechanisms of the model biases in a more process-oriented manner. For example, details of the cloud and precipitation process can be investigated using high-frequency, full vertical resolution JMIP data with the aid of satellite simulator (e.g. Suzuki et al. 2015 for warm rain process; Bodas-Salcedo et al. 2008 for global cloud). The results that AFES and SINTEX-F2 relatively better simulates climatology of Asian summer monsoon (Section 4.5) might give us a hint to improve climatology 
in the other models, though further in-depth investigation is needed to understand the reasons for the difference of the simulated Asian summer monsoon among the models. We also point out the usefulness of the JMIP framework for exchanging information on model development and performance; this will aid the promotion of our overall scientific effort and assist in the potential future sharing some part of the physics packages; thus reducing the costs of multi-model development.

We would like to present this study as the first phase of JMIP (JMIP1), in which we have focused on the climatological aspects simulated by the atmospheric models. Another concern that modeling groups might share relates to model performance in weekly-to-seasonal scale weather forecasting. Recently, Nakano et al. (2017) conducted the Global $7 \mathrm{~km}$ mesh nonhydrostatic Model Intercomparison Project for improving TYphoon forecast (TYMIP-G7) to investigate the impact of using high resolution models on forecasting skill, in which NICAM, MSSG, DFSM (a double Fourier series model developed in MRI), and GSM were included. Considering that JAMSTEC not only possesses a wide variety of GCMs and the Earth Simulator, but also observation vessels, intensive collaboration between modeling and observation groups could also be an important future step for pushing our science forward. Such a collaboration has already been conducted in the Cooperative Indian Ocean Experiment on Intraseasonal Variability in the Year 2011 (CINDY2011)/Dynamics of the MJO (DYNAMO) intensive observation, in which NICAM was routinely performed to provide near real-time forecasting (Nasuno et al. 2017).

\section{Acknowledgements}

We would like to thank Drs. Mikiko Fujita and Akira Yamazaki for providing comments on the manuscript and discussion in JMIP meeting. Our thanks also go to Dr. Yohei Yamada for discussion in JMIP meeting. AFES integrations are supported by the Japan Society for the Promotion of Science (JSPS) KAKENHI Grants 25242038, 26707025, 26287110, 15H01606, 16K12591, and $16 \mathrm{H} 01846$ as well the Grant-in-Aid for Scientific Research on Innovative Areas 22106008 ("A 'hot spot' in the climate system: Extratropical air-sea interaction under the East Asian monsoon system") of KAKENHI from the Ministry of Education, Culture, Sports, Science and Technology (MEXT). The AMIP simulation by MIOC5 was supported by the KAKUSHIN program, MEXT, Japan and performed using the Earth Simulator. The AMIP simulation by NICAM.12 was performed on the $\mathrm{K}$ computer at the RIKEN Advanced Research Institute for Computational Science (Proposal number: hp120279, hp130010 and hp140219), which was supported by Strategic Programs for Innovative Research (SPIRE) Field 3 (Projection of Planet Earth Variations for Mitigating Natural Disasters) promoted by MEXT. The SINTEX-F1/F2 were run by the Earth Simulator at JAMSTEC. We are grateful to Drs. Wataru Sasaki, Jing-Jia Luo, Sebastian Masson, and our European colleagues of INGV/CMCC, L'OCEAN, and MPI for their contribution to developing the prototype of the systems.

\section{References}

Adler, R.F., and Coauthors (2003), The version-2 global precipitation climatology project (GPCP) monthly precipitation analysis (1979-present), J. Hydrometeorol., 4, 1147-1167, doi:10.1175/1525-7541(2003)004<1147: TVGPCP $>2.0 . \mathrm{CO} ; 2$.

Bjerknes, J. (1964), Atlantic air-sea interaction, Adv. Geophys., 10, 1-82, doi:10.1016/S0065-2687(08)60005-9.

Bjerknes, J. (1969), Atmospheric teleconnections from the equatorial Pacific, Mon. Wea. Rev., 97, 163-172, doi:10. 1175/1520-0493(1969)097<0163:ATFTEP>2.3.CO;2.

Bodas-Salcedo, A., M.J. Webb, M.E. Brooks, M.A. Ringer, K.D. Williams, S.F. Milton, and D.R. Wilson (2008), Evaluating cloud systems in the Met Office global forecast model using simulated CloudSat radar reflectivities, J. Geophys. Res., 113, D00A13, doi:10.1029/2007JD009620.

Brinkop, S. and E. Roeckner (1995), Sensitivity of a general circulation model to parameterizations of cloudturbulence interactions in the atmospheric boundary layer, Tellus A, 47, 197-220, doi:10.1034/j.1600-0870. 1995.t01-1-00004.x.

Chen, Y.-W., T. Seiki, C. Kodama, M. Satoh, A.T. Noda, and Y. Yamada (2016), High Cloud Responses to Global Warming Simulated by Two Different Cloud Microphysics Schemes Implemented in the Nonhydrostatic Icosahedral Atmospheric Model (NICAM), J. Clim., 29, 5949-5964, doi:10.1175/ JCLI-D-15-0668.1.

Chiang, J.C.H. and D.J. Vimont (2004), Analogous Pacific and Atlantic meridional modes of tropical atmosphere- 
ocean variability, J. Clim., 17, 4143-4158, doi:10.1175/ JCLI4953.1.

Chikamoto, Y., and Coauthors (2013), An overview of decadal climate predictability in a multi-model ensemble by climate model MIROC, Clim. Dyn., 40, 1201-1222, doi: 10.1007/s00382-012-1351-y.

Chikira, M. and M. Sugiyama (2010), A cumulus parameterization with state-dependent entrainment rate. Part I: Description and sensitivity to temperature and humidity profiles, J. Atmos. Sci., 67, 2171-2193, doi:10.1175/2010JAS3316.1

Chikira, M. and M. Sugiyama (2013), Eastward-propagating intraseasonal oscillation represented by ChikiraSugiyama cumulus parameterization. Part I: comparison with observation and reanalysis, J. Atmos. Sci., 70, 3920-3939, doi:10.1175/JAS-D-13-034.1.

Doi, T., S.K. Behera, and T. Yamagata (2013), Predictability of the Ningaloo Niño/Niña, Sci. Rep., 3, 2892, doi:10.1038/ srep02892.

Doi, T., S.K. Behera, and T. Yamagata (2015a), An interdecadal regime shift in rainfall predictability related to the Ningaloo Niño in the late 1990s, J. Geophys. Res. Oceans, 120, 1388-1396, doi:10.1002/2014JC010562.

Doi, T., C. Yuan, S.K. Behera, and T. Yamagata (2015b), Predictability of the California Niño/Niña, J. Clim., 28, 7237-7249, doi:10.1175/JCLI-D-15-0112.1.

Doi, T., S.K. Behera, and T. Yamagata (2016), Improved seasonal prediction using the SINTEX-F2 coupled model, $J$. Adv. Model. Earth Syst., 8, 1847-1867, doi:10.1002/ 2016MS000744.

Doi, T., A. Storto, S.K. Behera, A. Navarra, and T. Yamagata (2017), Improved prediction of the Indian Ocean Dipole Mode by use of subsurface ocean observations, J. Clim., 30, 7953-7970, doi:10.1175/JCLI-D-16-0915.1.

Donohoe, A. and D.S. Battisti (2011), Atmospheric and surface contributions to planetary albedo, J. Clim., 24, 4402 4418, doi:10.1175/2011JCLI3946.1.

Emanuel, K.A. (1991), A scheme for representing cumulus convection in large-scale models, J. Atmos. Sci., 48, 2313-2335, doi:10.1175/1520-0469(1991)048 $<2313$ :ASFRCC>2.0.CO;2.

Emanuel, K.A. and M. Živković-Rothman (1999), Development and evaluation of a convection scheme for use in climate models, J. Atmos. Sci., 56, 1766-1782, doi:10.1175/ 1520-0469(1999)056<1766:DAEOAC>2.0.CO;2.

Enomoto, T., A. Kuwano-Yoshida, N. Komori, and W. Ohfuchi (2008), Description of AFES 2: Improvements for highresolution and coupled simulations. High Resolution Numerical Modelling of the Atmosphere and Ocean, K. Hamilton and W. Ohfuchi Eds., Springer, New York, 7797.
Eyring, V., and Coauthors (2008), Overview of the new CCMVal reference and sensitivity simulations in support of upcoming ozone and climate assessments and the planned SPARC CCMVal report, SPARC Newsl., 30, 20-26.

Eyring, V., and Coauthors (2013), Long-term ozone changes and associated climate impacts in CMIP5 simulations, $J$. Geophys. Res. Atmos., 118, 5029-5060, doi:10.1002/jgrd. 50316.

Fichefet, T. and M.A. Morales Maqueda (1997), Sensitivity of a global sea ice model to the treatment of ice thermodynamics and dynamics, J. Geophys. Res. Oceans, 102, 12609-12646, doi:10.1029/97JC00480.

Fortuin, J.P.F. and H. Kelder (1998), An ozone climatology based on ozonesonde and satellite measurements, $J$. Geophys. Res. Atmos., 103, 31709-31734, doi:10.1029/ 1998JD200008.

Fouquart, Y. and B. Bonnell (1980), Computations of solar heating of the Earth's atmosphere: A new parameterization, Contrib. Atmos. Phys., 53, 35-62.

Fukutomi, Y., C. Kodama, Y. Yamada, A.T. Noda, and M. Satoh (2015), Tropical synoptic-scale wave disturbances over the western Pacific simulated by a global cloud-system resolving model, Theor. Appl. Climatol., 124, 737-755, doi:10.1007/s00704-015-1456-4.

Gates, W.L. (1992), AMIP: The atmospheric model intercomparison project, Bull. Amer. Meteor. Soc., 73, 1962-1970, doi:10.1175/1520-0477(1992)073 $<$ 1962:atamip >2.0.CO;2.

Grabowski, W.W. (2006), Impact of explicit atmosphere-ocean coupling on MJO-like coherent structures in idealized aquaplanet simulations, J. Atmos. Sci., 63, 2289-2306, doi:10.1175/JAS3740.1.

Gualdi, S., A. Navarra, E. Guilyardi, and P. Delecluse (2003), Assessment of the tropical Indo-Pacific climate in the SINTEX CGCM, Ann. Geophys., 46, 1-26.

Guan, Z. and T. Yamagata (2003), The unusual summer of 1994 in East Asia: IOD teleconnections, Geophys. Res. Lett., 30, 1544, doi:10.1029/2002GL016831.

Hansen, J. and M. Sato (2004), Greenhouse gas growth rates, Proc. Natl. Acad. Sci., 101, 16109-16114, doi:10.1073/ pnas.0406982101.

Hirota, N. and Y.N. Takayabu (2013), Reproducibility of precipitation distribution over the tropical oceans in CMIP5 multi-climate models compared to CMIP3, Clim. Dyn., 41, 2909-2920, doi:10.1007/s00382-013-1839-0.

Holland, G.J. (1995), Scale interaction in the western Pacific monsoon, Meteorol. Atmos. Phys., 56, 57-79, doi:10. 1007/BF01022521.

Jin, E.K., and Coauthors (2008), Current status of ENSO prediction skill in coupled ocean-atmosphere models, Clim. Dyn., 31, 647-664, doi:10.1007/s00382-008-0397- 
3.

Kamae, Y. and M. Watanabe (2013), Tropospheric adjustment to increasing $\mathrm{CO}_{2}$ : its timescale and the role of landsea contrast, Clim. Dyn., 41, 3007-3024, doi:10.1007/ s00382-012-1555-1.

Kikuchi, K., C. Kodama, T. Nasuno, M. Nakano, H. Miura, M. Satoh, A.T. Noda, and Y. Yamada (2017), Tropical intraseasonal oscillation simulated in an AMIP-type experiment by NICAM, Clim. Dyn., 48, 2507-2528, doi: 10.1007/s00382-016-3219-z.

Klimont, Z., S.J. Smith, and J. Cofala (2013), The last decade of global anthropogenic sulfur dioxide: 2000-2011 emissions, Environ. Res. Lett., 8, 014003, doi:10.1088/ 1748-9326/8/1/014003.

Kobayashi, C., H. Endo, Y. Ota, S. Kobayashi, H. Onoda, Y. Harada, K. Onogi, and H. Kamahori (2014), Preliminary results of the JRA-55C, an atmospheric reanalysis assimilating conventional observations only, SOLA, 10, 78-82, doi:10.2151/sola.2014-016.

Kobayashi, S., and Coauthors (2015), The JRA-55 reanalysis: general specifications and basic characteristics, $J$. Meteorol. Soc. Japan. Ser. II, 93, 5-48, doi:10.2151/jmsj. 2015-001.

Kodama, C., and Coauthors (2015), A 20-year climatology of a NICAM AMIP-type simulation, J. Meteorol. Soc. Japan. Ser. II, 93, 393-424, doi:10.2151/jmsj.2015-024.

Koepke, P., M. Hess, I. Schult, and E.P. Shettle (1997), Global aerosol data set, Report No. 243, Hamburg, 1-44 pp.

Kuwano-Yoshida, A. (2014), Using the local deepening rate to indicate extratropical cyclone activity, SOLA, 10, 199203, doi:10.2151/sola.2014-042.

Kuwano-Yoshida, A. and T. Enomoto (2013), Predictability of explosive cyclogenesis over the Northwestern Pacific region using ensemble reanalysis, Mon. Wea. Rev., 141, 3769-3785, doi:10.1175/MWR-D-12-00161.1.

Kuwano-Yoshida, A. and S. Minobe (2017), Storm-track response to SST fronts in the northwestern Pacific region in an AGCM, J. Clim., 30, 1081-1102, doi:10.1175/JCLI-D16-0331.1.

Kuwano-Yoshida, A., T. Enomoto, and W. Ohfuchi (2010a), An improved PDF cloud scheme for climate simulations, $Q$. J. R. Meteorol. Soc., 136, 1583-1597, doi:10.1002/qj.660.

Kuwano-Yoshida, A., S. Minobe, and S.-P. Xie (2010b), Precipitation response to the Gulf stream in an atmospheric GCM, J. Clim., 23, 3676-3698, doi:10.1175/ 2010JCLI3261.1.

Langenbrunner, B. and J.D. Neelin (2013), Analyzing ENSO teleconnections in CMIP models as a measure of model fidelity in simulating precipitation, J. Clim., 26, 44314446, doi:10.1175/JCLI-D-12-00542.1.

Liang, X.-Z., W.-C. Wang, and J.S. Boyle (1997), Atmospheric ozone climatology for use in general circulation models, $<$ https://pcmdi.llnl.gov/report/ab43.html>, (accessed 2018-12-14).

Loeb, N.G., B.A. Wielicki, D.R. Doelling, G.L. Smith, D.F. Keyes, S. Kato, N. Manalo-Smith, and T. Wong (2009), Toward optimal closure of the Earth's top-ofatmosphere radiation budget, J. Clim., 22, 748-766, doi:10.1175/2008JCLI2637.1.

Lohmann, U., P. Stier, C. Hoose, S. Ferrachat, S. Kloster, E. Roeckner, and J. Zhang (2007), Cloud microphysics and aerosol indirect effects in the global climate model ECHAM5-HAM, Atmos. Chem. Phys., 7, 3425-3446, doi:10.5194/acp-7-3425-2007.

Luo, J.-J., S. Masson, S. Behera, S. Shingu, and T. Yamagata (2005a), Seasonal climate predictability in a coupled OAGCM using a different approach for ensemble forecasts, J. Clim., 18, 4474-4497, doi:10.1175/JCLI3526.1.

Luo, J.-J., S. Masson, E. Roeckner, G. Madec, and T. Yamagata (2005b), Reducing climatology bias in an oceanatmosphere CGCM with improved coupling physics, $J$. Clim., 18, 2344-2360, doi:10.1175/JCLI3404.1.

Luo, J.-J., S. Masson, S. Behera, and T. Yamagata (2007), Experimental forecasts of the Indian Ocean dipole using a coupled OAGCM, J. Clim., 20, 2178-2190, doi:10.1175/JCLI4132.1.

Luo, J.-J., S. Behera, Y. Masumoto, H. Sakuma, and T. Yamagata (2008a), Successful prediction of the consecutive IOD in 2006 and 2007, Geophys. Res. Lett., 35, L14S02, doi:10.1029/2007GL032793.

Luo, J.-J., S. Masson, S. K. Behera, and T. Yamagata (2008b), Extended ENSO predictions using a fully coupled oceanatmosphere model, J. Clim., 21, 84-93.

Madec, G. (2008), NEMO ocean engine, version 3.0. Note $d u$ Pôle modélisation l'Institut Pierre-Simon Laplace 27, ISSN 1288-1619, Inst. Pierre-Simon Laplace, Fr., 209 pp.

Madec, G., P. Delecluse, M. Imbard, and C. Levy (1998), OPA 8.1 ocean general circulation model reference manual. LODYC/IPSL Tech. Rep. Note 11, 91 pp.

Masson, S., P. Terray, G. Madec, J.-J. Luo, T. Yamagata, and K. Takahashi (2012), Impact of intra-daily SST variability on ENSO characteristics in a coupled model, Clim. Dyn., 39, 681-707, doi:10.1007/s00382-011-1247-2.

Medeiros, B. and B. Stevens (2011), Revealing differences in GCM representations of low clouds, Clim. Dyn., 36, 385399, doi:10.1007/s00382-009-0694-5.

Minobe, S., A. Kuwano-Yoshida, N. Komori, S.-P. Xie, and R.J. Small (2008), Influence of the Gulf Stream on the troposphere, Nature, 452, 206-209, doi:10.1038/nature06690.

Miura, H., M. Satoh, T. Nasuno, A.T. Noda, and K. Oouchi 
(2007), A Madden-Julian Oscillation event realistically simulated by a global cloud-resolving model, Science, 318, 1763-1765, doi:10.1126/science.1148443.

Miyakawa, T., and Coauthors (2014), Madden-Julian Oscillation prediction skill of a new-generation global model demonstrated using a supercomputer, Nat. Commun., 5, 3769, doi:10.1038/ncomms4769.

Miyamoto, Y., Y. Kajikawa, R. Yoshida, T. Yamaura, H. Yashiro, and H. Tomita (2013), Deep moist atmospheric convection in a subkilometer global simulation, Geophys. Res. Lett., 40, 4922-4926, doi:10.1002/grl.50944.

Miyoshi, T. and S. Yamane (2007), Local Ensemble Transform Kalman Filtering with an AGCM at a T159/L48 Resolution, Mon. Wea. Rev., 135, 3841-3861, doi: 10.1175/2007MWR1873.1.

Miyoshi, T., S. Yamane, and T. Enomoto (2007), The AFESLETKF Experimental Ensemble Reanalysis: ALERA, SOLA, 3, 45-48, doi:10.2151/sola.2007-012.

Miyoshi, T., K. Kondo, and K. Terasaki (2015), Big ensemble data assimilation in numerical weather prediction, Computer (Long Beach, Calif.), 48, 15-21, doi:10.1109/MC.2015.332.

Mizuta, R., and Coauthors (2012), Climate simulations using MRI-AGCM3.2 with 20-km grid, J. Meteorol. Soc. Japan. Ser. II, 90A, 233-258, doi:10.2151/jmsj.2012A12.

Mlawer, E.J., S.J. Taubman, P.D. Brown, M.J. Iacono, and S.A. Clough (1997), Radiative transfer for inhomogeneous atmospheres: RRTM, a validated correlated-k model for the longwave, J. Geophys. Res. Atmos., 102, 16663 16682, doi:10.1029/97JD00237.

Morcrette, J.-J. (1991), Radiation and cloud radiative properties in the European Centre for Medium Range Weather Forecasts forecasting system, J. Geophys. Res., 96, 9121, doi:10.1029/89JD01597.

Nakanishi, M. (2001), Improvement of the Mellor-Yamada turbulence closure model based on large-eddy simulation data, Boundary-Layer Meteorol., 99, 349-378, doi:10.1023/A:1018915827400.

Nakanishi, M. and H. Niino (2004), An improved Mellor-Yamada level-3 model with condensation physics: Its design and verification, Boundary-Layer Meteorol., 112, 1-31, doi:10.1023/B:BOUN.0000020164.04146.98.

Nakanishi, M. and H. Niino (2006), An improved Mellor-Yamada level-3 model: Its numerical stability and application to a regional prediction of advection fog, Boundary-Layer Meteorol., 119, 397-407, doi:10.1007/s10546-005-90308.

Nakano, M., and Coauthors (2017), Global $7 \mathrm{~km}$ mesh nonhydrostatic Model Intercomparison Project for improving TYphoon forecast (TYMIP-G7):
Experimental design and preliminary results, Geosci. Model Dev., 10, 1363-1381, doi:10.5194/gmd-10-13632017.

Nasuno, T., K. Kikuchi, M. Nakano, Y. Yamada, M. Ikeda, and H. Taniguchi (2017), Evaluation of the near real-time forecasts using a global nonhydrostatic model during the CINDY2011/DYNAMO, J. Meteorol. Soc. Japan. Ser. II, 95, 345-368, doi:10.2151/jmsj.2017-022.

Noda, A.T., K. Oouchi, M. Satoh, H. Tomita, S. Iga, and Y. Tsushima (2010), Importance of the subgrid-scale turbulent moist process: Cloud distribution in global cloud-resolving simulations, Atmos. Res., 96, 208-217, doi:10.1016/j.atmosres.2009.05.007.

Noda, A.T., K. Oouchi, M. Satoh, and H. Tomita (2012), Quantitative assessment of diurnal variation of tropical convection simulated by a global nonhydrostatic model without cumulus parameterization, J. Clim., 25, 51195134, doi:10.1175/JCLI-D-11-00295.1.

Nordeng, T.E. (1994), Extended versions of the convective parameterization scheme at ECMWF and their impact on the mean and transient activity of the model in the tropics, Reading, United Kingdom, 41pp.

Numaguti, A., M. Takahashi, T. Nakajima, and A. Sumi (1997), Description of CCSR/NIES atmospheric general circulation model, Study on the climate system and mass transport by a climate model, CGER's Supercomputer Monograph Report No. 3, 1-48.

O'Reilly, C.H., S. Minobe, and A. Kuwano-Yoshida (2016), The influence of the Gulf Stream on wintertime European blocking, Clim. Dyn., 47, 1545-1567, doi:10.1007/s00382-015-2919-0.

O'Reilly, C.H., S. Minobe, A. Kuwano-Yoshida, and T. Woollings (2017), The Gulf Stream influence on wintertime North Atlantic jet variability, Q. J. R. Meteorol. Soc., 143, 173183, doi:10.1002/qj.2907.

Ogawa, F., H. Nakamura, K. Nishii, T. Miyasaka, and A. KuwanoYoshida (2012), Dependence of the climatological axial latitudes of the tropospheric westerlies and storm tracks on the latitude of an extratropical oceanic front, Geophys. Res. Lett., 39, doi:10.1029/2011GL049922.

Ohfuchi, W., and Coauthors (2004), 10-km mesh meso-scale resolving simulations of the global atmosphere on the Earth Simulator: Preliminary outcomes of AFES (AGCM for the Earth Simulator), J. Earth Simulator, 1, 8-34.

Okajima, S., H. Nakamura, K. Nishii, T. Miyasaka, A. KuwanoYoshida, B. Taguchi, M. Mori, and Y. Kosaka (2018), Mechanisms for the maintenance of the wintertime basinscale atmospheric response to decadal SST variability in the North Pacific subarctic frontal zone, J. Clim., 31, $297-$ 315, doi:10.1175/JCLI-D-17-0200.1.

Pauluis, O. and S. Garner (2006), Sensitivity of radiative- 
convective equilibrium simulations to horizontal resolution, J. Atmos. Sci., 63, 1910-1923, doi:10.1175/JAS3705.1.

Peng, M.S., J.A. Ridout, and T.F. Hogan (2004), Recent modifications of the Emanuel convective scheme in the navy operational global atmospheric prediction system, Mon. Wea. Rev., 132, 1254-1268, doi:10.1175/15200493(2004)132<1254:RMOTEC > 2.0.CO;2.

Randall, D., M. Khairoutdinov, A. Arakawa, and W. Grabowski (2003), Breaking the cloud parameterization deadlock, Bull. Amer. Meteor. Soc., 84, 1547-1564, doi:10.1175/BAMS-84-11-1547.

Rayner, N.A., D.E. Parker, E.B. Horton, C.K. Folland, L.V. Alexander, D.P. Rowell, E.C. Kent, and A. Kaplan (2003), Global analyses of sea surface temperature, sea ice, and night marine air temperature since the late nineteenth century, J. Geophys. Res., 108, 4407, doi:10.1029/2002JD002670.

Reynolds, R.W., N.A. Rayner, T.M. Smith, D.C. Stokes, and W. Wang (2002), An improved in situ and satellite SST analysis for climate, J. Clim., 15, 1609-1625, doi:10.1175/ 1520-0442(2002)015<1609:AIISAS>2.0.CO;2.

Reynolds, R.W., T.M. Smith, C. Liu, D.B. Chelton, K.S. Casey, and M.G. Schlax (2007), Daily high-resolution-blended analyses for sea surface temperature, J. Clim., 20, 5473 5496, doi:10.1175/2007JCLI1824.1.

Roeckner, E., and Coauthors (1996), The atmospheric general circulation model ECHAM4: Model description and simulation of present-day climate, Max-Planck-Institut fur Meteorol. Rep., 218, 90 pp.

Roeckner, E., and Coauthors (2003), The atmospheric general circulation model ECHAM5. Part I: model description. MPI-Rep. 349, Max-Planck-Institut für Meteorol. Hamburg, Ger., 349, 140 pp.

Saji, N.H., B.N. Goswami, P.N. Vinayachandran, and T. Yamagata (1999), A dipole mode in the tropical Indian Ocean, Nature, 401, 360-363, doi:10.1038/43854.

Sasaki, W., K.J. Richards, and J.-J. Luo (2013), Impact of vertical mixing induced by small vertical scale structures above and within the equatorial thermocline on the tropical Pacific in a CGCM, Clim. Dyn., 41, 443-453, doi:10.1007/s00382-012-1593-8.

Sato, K., J. Inoue, A. Yamazaki, J.-H. Kim, M. Maturilli, K. Dethloff, S.R. Hudson, and M.A. Granskog (2017), Improved forecasts of winter weather extremes over midlatitudes with extra Arctic observations, J. Geophys. Res. Oceans, 122, 775-787, doi:10.1002/2016JC012197.

Satoh, M., T. Matsuno, H. Tomita, H. Miura, T. Nasuno, and S. Iga (2008), Nonhydrostatic icosahedral atmospheric model (NICAM) for global cloud resolving simulations, J. Comput. Phys., 227, 3486-3514, doi:10.1016/j.jcp.2007.02.006

Satoh, M., and Coauthors (2014), The non-hydrostatic icosahedral atmospheric model: Description and development, Prog. Earth Planet. Sci., 1, 18, doi:10.1186/s40645-014-0018-1.

Satoh, M., Y. Yamada, M. Sugi, C. Kodama, and A.T. Noda (2015), Constraint on future change in global frequency of tropical cyclones due to global warming, J. Meteorol. Soc. Japan. Ser. II, 93, 489-500, doi:10.2151/jmsj.2015025 .

Seiki, T. and T. Nakajima (2014), Aerosol effects of the condensation process on a convective cloud simulation, $J$. Atmos. Sci., 71, 833-853, doi:10.1175/JAS-D-12-0195.1.

Seiki, T., C. Kodama, A.T. Noda, and M. Satoh (2015), Improvement in Global Cloud-System-Resolving Simulations by Using a Double-Moment Bulk Cloud Microphysics Scheme, J. Clim., 28, 2405-2419, doi:10.1175/JCLI-D-14-00241.1.

Sekiguchi, M. and T. Nakajima (2008), A k-distributionbased radiation code and its computational optimization for an atmospheric general circulation model, $J$. Quant. Spectrosc. Radiat. Transf., 109, 2779-2793, doi:10.1016/j.jqsrt.2008.07.013.

Shibata, K., M. Deushi, T.T. Sekiyama, and H. Yoshimura (2005), Development of an MRI chemical transport model for the study of stratospheric chemistry, Pap. Meteor. Geophys., 55, 75-119, doi:10.2467/mripapers.55.75.

Shingu, S., and Coauthors (2002), A 26.58 Tflops global atmospheric simulation with the spectral transform method on the Earth Simulator, Proceedings of the ACM/IEEE SC 2002 Conference (SC'02), IEEE.

Sperber, K.R., H. Annamalai, I.-S. Kang, A. Kitoh, A. Moise, A. Turner, B. Wang, and T. Zhou (2013), The Asian summer monsoon: an intercomparison of CMIP5 vs. CMIP3 simulations of the late 20th century, Clim. Dyn., 41, 2711-2744, doi:10.1007/s00382-012-1607-6.

Sugimoto, N., A. Yamazaki, T. Kouyama, H. Kashimura, T. Enomoto, and M. Takagi (2017), Development of an ensemble Kalman filter data assimilation system for the Venusian atmosphere, Sci. Rep., 7, 9321, doi:10.1038/s41598-017-09461-1.

Suzuki, K., G. Stephens, A. Bodas-Salcedo, M. Wang, J.-C. Golaz, T. Yokohata, and T. Koshiro (2015), Evaluation of the Warm Rain Formation Process in Global Models with Satellite Observations, J. Atmos. Sci., 72, 39964014, doi:10.1175/JAS-D-14-0265.1.

Takagi, M., N. Sugimoto, H. Ando, and Y. Matsuda (2018), Three-dimensional structures of thermal tides simulated by a Venus GCM, J. Geophys. Res. Planets, 123, 335352, doi:10.1002/2017JE005449.

Takahashi, K., X. Peng, R. Onishi, M. Ohdaira, K. Goto, H. 
Fuchigami, and T. Sugimura (2008), Impact of coupled nonhydrostatic atmosphere-ocean-land model with high resolution, K. Hamilton and W. Ohfuch (Eds.) High Resolution Numerical Modelling of the Atmosphere and Ocean, Springer, NY, 261-273.

Takata, K., S. Emori, and T. Watanabe (2003), Development of the minimal advanced treatments of surface interaction and runoff, Glob. Planet. Change, 38, 209-222, doi:10.1016/S0921-8181(03)00030-4.

Takemura, T., T. Nozawa, S. Emori, T.Y. Nakajima, and T. Nakajima (2005), Simulation of climate response to aerosol direct and indirect effects with aerosol transportradiation model, J. Geophys. Res., 110, D02202, doi:10.1029/2004JD005029.

Taylor, K.E., D. Williamson, and F. Zwiers (2000), The sea surface temperature and sea-ice concentration boundary conditions for AMIP II simulations.

Tiedtke, M. (1989), A comprehensive mass flux scheme for cumulus parameterization in large-scale models, Mon. Wea. Rev., 117, 1779-1800.

Tomita, H. (2008). New microphysical schemes with five and six categories by diagnostic generation of cloud ice, J. Meteorol. Soc. Japan. Ser. II, 86A, 121-142, doi:10.2151/jmsj.86A.121.

Tomita, H. and M. Satoh (2004), A new dynamical framework of nonhydrostatic global model using the icosahedral grid, Fluid Dyn. Res., 34, 357-400, doi:10.1016/j.fluiddyn.2004.03.003.

Valcke, S., L. Terray, and A. Piacentini (2000), The OASIS coupler user guide version 2.4. CERFACE Tech. Rep. TR/CGMC/00-10, Toulouse, Fr., 85 pp.

Valcke, S., A. Caubel, R. Vogelsang, and D. Declat (2004), OASIS3 ocean atmosphere sea ice soil user's guide. Tech. Rep. TR/CMGC/04/68, CERFACS, Toulouse, Fr, 70 pp.

Wang, B., R. Wu, and X. Fu (2000), Pacific-East Asian teleconnection: How does ENSO affect East Asian climate?, J. Clim., 13, 1517-1536, doi:10.1175/15200442(2000)013<1517:PEATHD>2.0.CO;2.

Wang, B., R. Wu, and K.-M. Lau (2001), Interannual variability of the Asian summer monsoon: Contrasts between the Indian and the western North Pacific-East Asian monsoons, J. Clim., 14, 4073-4090, doi:10.1175/15200442(2001)014<4073:IVOTAS>2.0.CO;2.

Wang, B., Q. Ding, X. Fu, I.-S. Kang, K. Jin, J. Shukla, and F. Doblas-Reyes (2005), Fundamental challenge in simulation and prediction of summer monsoon rainfall, Geophys. Res. Lett., 32, L15711, doi:10.1029/2005GL022734.

Wang, H. and W. Su (2013), Evaluating and understanding top of the atmosphere cloud radiative effects in Intergovernmental Panel on Climate Change (IPCC)
Fifth Assessment Report (AR5) Coupled Model Intercomparison Project Phase 5 (CMIP5) models using satellite observations, J. Geophys. Res. Atmos., 118, 683-699, doi:10.1029/2012JD018619.

Wang, R., and Coauthors (2012), Black Carbon Emissions in China from 1949 to 2050, Environ. Sci. Technol., 46, 7595-7603, doi:10.1021/es3003684.

Watanabe, M. and F.-F. Jin (2003), A moist linear baroclinic model: Coupled dynamical-convective response to El Niño, J. Clim., 16, 1121-1139, doi:10.1175/15200442(2003)16<1121:AMLBMC>2.0.CO;2.

Watanabe, M., S. Emori, M. Satoh, and H. Miura (2009), A PDF-based hybrid prognostic cloud scheme for general circulation models, Clim. Dyn., 33, 795-816, doi:10.1007/s00382-008-0489-0.

Watanabe, M., and Coauthors (2010), Improved climate simulation by MIROC5: Mean states, variability, and climate sensitivity, J. Clim., 23, 6312-6335, doi:10.1175/2010JCLI3679.1.

Watanabe, M., J.-S. Kug, F.-F. Jin, M. Collins, M. Ohba, and A.T. Wittenberg (2012), Uncertainty in the ENSO amplitude change from the past to the future, Geophys. Res. Lett., 39, L20703, doi:10.1029/2012GL053305.

Watanabe, M., Y. Kamae, M. Yoshimori, A. Oka, M. Sato, M. Ishii, T. Mochizuki, and M. Kimoto (2013), Strengthening of ocean heat uptake efficiency associated with the recent climate hiatus, Geophys. Res. Lett., 40, 3175-3179, doi:10.1002/grl.50541.

Wielicki, B.A., B.R. Barkstrom, E.F. Harrison, R.B. Lee, G. Louis Smith, and J.E. Cooper (1996), Clouds and the earth's radiant energy system (CERES): An earth observing system experiment, Bull. Amer. Meteor. Soc., 77, 853-868, doi:10.1175/1520-0477(1996)077 $<0853$ :CATERE $>2.0 . \mathrm{CO} ; 2$.

Willison, J., W.A. Robinson, and G.M. Lackmann (2013), The Importance of resolving mesoscale latent heating in the North Atlantic storm track, J. Atmos. Sci., 70, 2234-2250, doi:10.1175/JAS-D-12-0226.1.

Wilson, D.R. and S.P. Ballard (1999), A microphysically based precipitation scheme for the UK meteorological office unified model, Q. J. R. Meteorol. Soc., 125, 1607-1636, doi:10.1002/qj.49712555707.

Xie, S.-P., K. Hu, J. Hafner, H. Tokinaga, Y. Du, G. Huang, and T. Sampe (2009), Indian ocean capacitor effect on Indo-Western Pacific climate during the summer following El Niño, J. Clim., 22, 730-747, doi:10.1175/2008JCLI2544.1.

Yamada, Y., M. Satoh, M. Sugi, C. Kodama, A.T. Noda, M. Nakano, and T. Nasuno (2017), Response of tropical cyclone activity and structure to global warming in a high-resolution global nonhydrostatic model, J. Clim., 30, 
9703-9724, doi:10.1175/JCLI-D-17-0068.1.

Yamagata, T., Y. Morioka, and S.K. Behera (2016), Old and new faces of climate variations, S.K. Behera and T. Yamagata (Eds.) World Scientific Series on Asia-Pacific Weather and Climate: Volume 7, IndoPacific Climate Variability and Predictability, 1-23 pp., doi:10.1142/9789814696623_0001.

Yashiro, H., Y. Kajikawa, Y. Miyamoto, T. Yamaura, R. Yoshida, and H. Tomita (2016a), Resolution dependence of the diurnal cycle of precipitation simulated by a global cloud-system resolving model, SOLA, 12, 272-276, doi:10.2151/sola.2016-053.

Yashiro, H., K. Terasaki, T. Miyoshi, and H. Tomita (2016b), Performance evaluation of a throughput-aware framework for ensemble data assimilation: the case of NICAM-LETKF, Geosci. Model Dev., 9, 2293-2300, doi:10.5194/gmd-9-2293-2016.

Yuan, C. and T. Yamagata (2015), Impacts of IOD, ENSO and ENSO Modoki on the Australian winter wheat yields in recent decades, Sci. Rep., 5, 17252, doi:10.1038/srep17252. 